PERCEPTUAL RESPONSES TO HIGH INTENSITY INTERVAL TRAINING AMONG OVERWEIGHT AND OBESE INDIVIDUALS

by

John Thomas Halvorson

A thesis submitted in partial fulfillment of the requirements for the degree

of

Master of Science

in

Health and Human Development

MONTANA STATE UNIVERSITY

Bozeman, Montana

April 2016 
CCOPYRIGHT

By

John Thomas Halvorson

2016

All Rights Reserved 


\section{ACKNOWLEDGEMENTS}

My utmost respect and appreciation goes to my advisor, Dr. Mary Miles, who has been a constant support, inspiration, and guidance throughout my time at Montana State University. Thank you very much for the valuable wisdom and encouragement. I would also like to thank my graduate committee for their advice and guidance, Dr. Carmen Byker-Shanks and Dr. John Seifert. I would also like to thank Morgan Julian and Paige Welsch for the constant helping hand during the exercise conditions.

Thank you to my wonderful and beautiful wife, Annaliese Halvorson, who has been of constant love and support through this process of thick and thin. The unconditional love and support has been something that cannot truly be put into words. The encouragement to push through the hard times, enjoy and embrace the good times, and live for the moment while still keeping an eye on the future has been insight and support that will never be forgotten. Your unending love has been the biggest blessing any person could ask for.

Last but certainly not least to my family, Cheryl Keeley, Tom Halvorson, Kevin Halvorson, Robin Ullas, Brooke Halvorson, Grandma Karen, Grandpa Don, and Grandma Joyce. The unconditional love and support to always reach for the moon and know that even if I miss, I end up in the stars will never be forgotten. Your love, support, and laughter has been a true blessing. 
TABLE OF CONTENTS

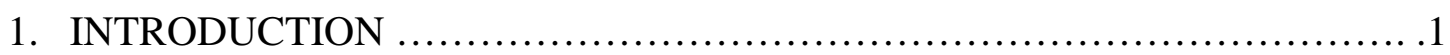

Development of the Problem .....................................................................

Purpose

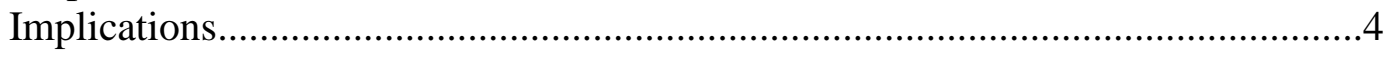

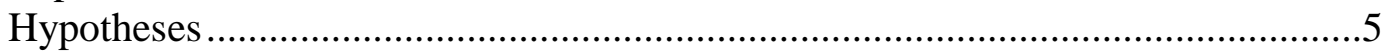

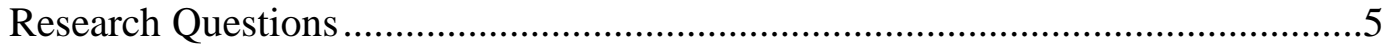

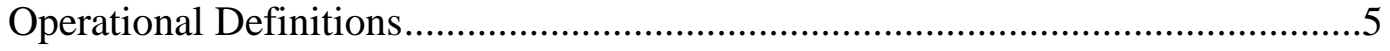

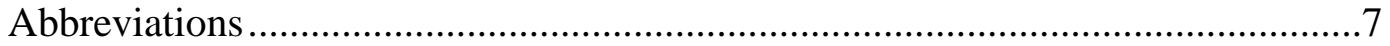

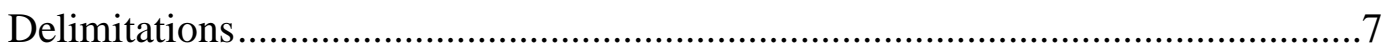

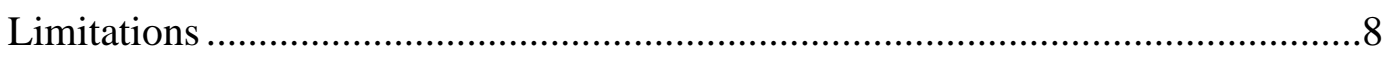

2. LITERATURE REVIEW.............................................. 10

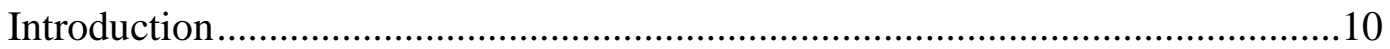

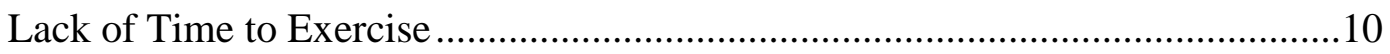

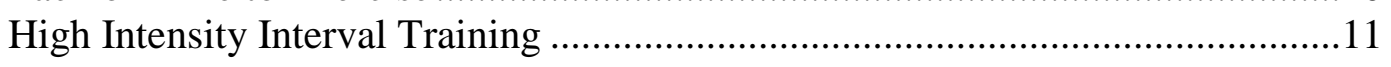

Practical Low-Volume High Intensity Interval

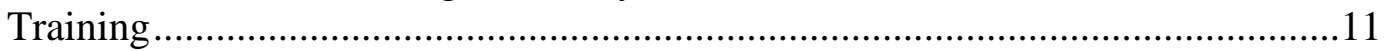

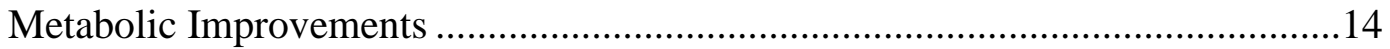

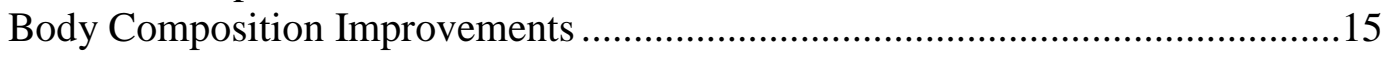

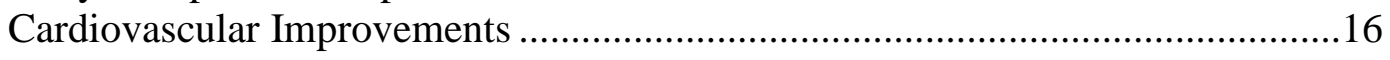

Feelings of Enjoyment Assessments............................................................ 17

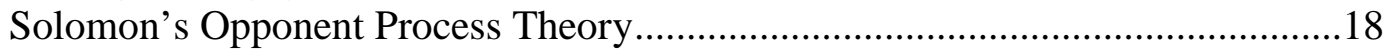

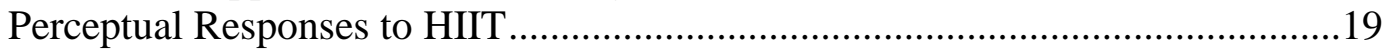

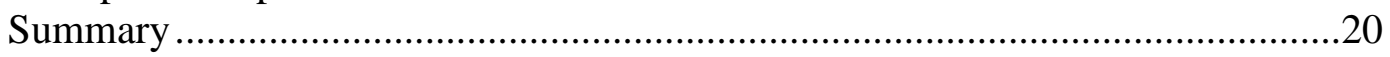

3. PERCEPTUAL RESPONSES TO HIGH

INTENSITY INTERVAL TRAINING

AMONG OVERWEIGHT AND

OBESE INDIVIDUALS ...............................................22

Contributions of Authors and Co-Authors..................................................22

Manuscript Information Page ...................................................................23

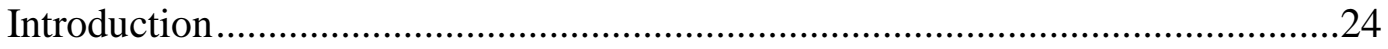

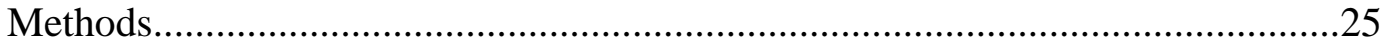

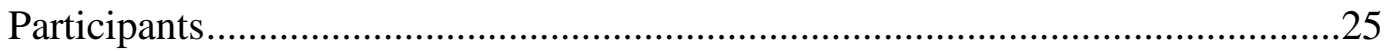

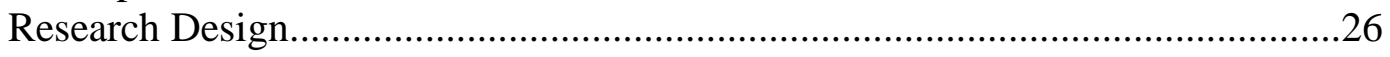

Informed Consent....................................................................................26

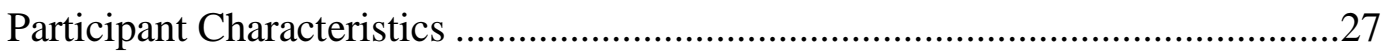

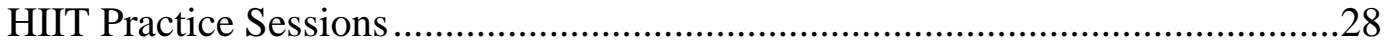

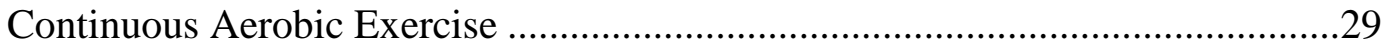


TABLE OF CONTENTS - CONTINUED

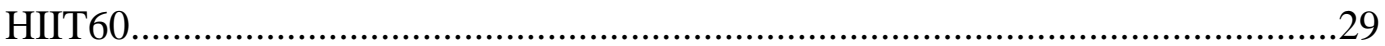

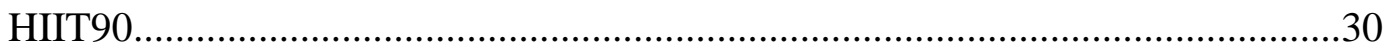

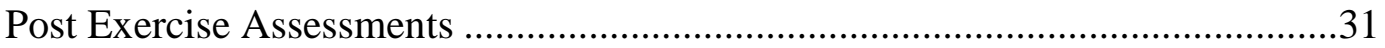

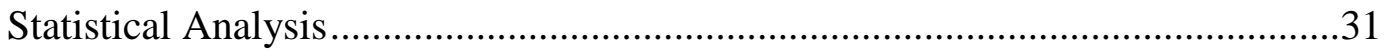

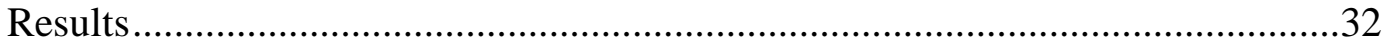

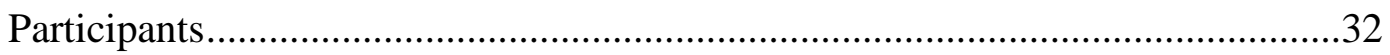

Exercise Requirements................................................................................33

Exercise Perceptions During the Exercise .......................................................35

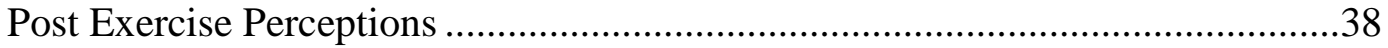

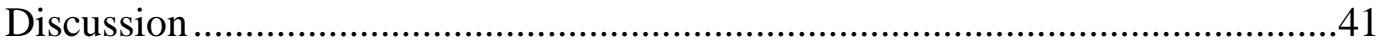

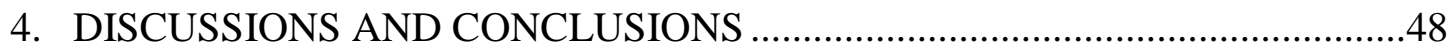

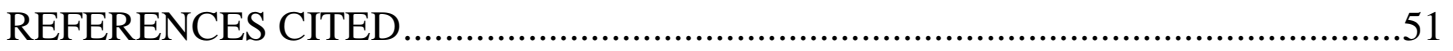

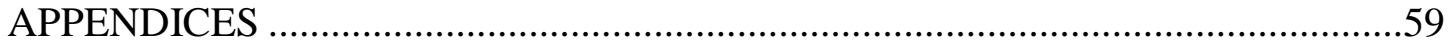

APENDIX A: AHA/ACSM Health/Fitness

Facility Preparticipation Screening

Questionnaire 60

APPENDIX B: Subject Consent Form for

Participation in Human Research at

Montana State University .....................................................62

APPENDIX C: Ratings of Perceived Exertion ................................................. 71

APPENDIX D: Exercise Enjoyment Scale...................................................73

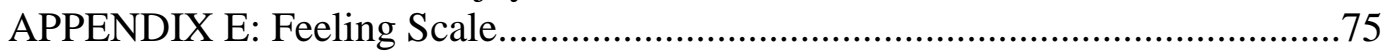

APPENDIX F: Physical Activity Enjoyment Scale............................................77

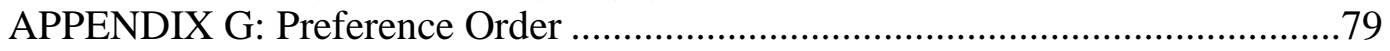




\section{LIST OF TABLES}

Table

2.1 Significant HIIT studies with protocols, participants, interventions, and significant outcomes

3.1 Characteristics of participants 32

3.2 Average heart rates during the exercise

3.3 Post oxygen consumption immediately and 30 minutes following the exercise conditions.

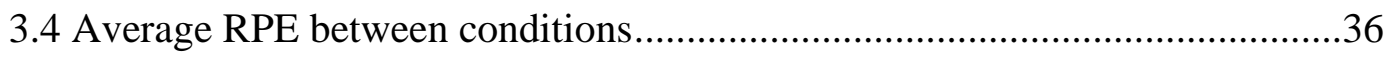

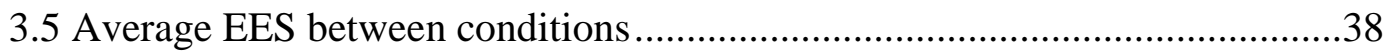

3.6 FS 5 minutes and 35 minutes following the exercise conditions

3.7 5 minute post FS between conditions .40

3.835 minute post FS between conditions

3.9 PACES 5 minutes and 35 minutes following the exercise conditions

3.10 5 minute post PACES between conditions

3.11 35 minute post PACES between conditions

3.12 Preference order of the conditions 


\section{LIST OF FIGURES}

Figure

3.1 Design of the exercise visits

3.2 Average heart rate at each time points during continuous aerobic, HIIT60, and HIIT90.

3.3 Average RPE at each time point during continuous aerobic, HIIT60, and HIIT90

3.4 Average EES at each time point during continuous aerobic, HIIT60, and HIIT90 


\begin{abstract}
Poor diet and exercise adherence is resulting in the rise of chronic diseases. High intensity interval training (HIIT) has the ability to improve adherence as it takes less time to complete and has changes in intensity and monotony. The aim of the study was to analyze whether participants prefer HIIT in comparison to continuous aerobic exercise (CON). The hypothesis was that HIIT would be preferred and enjoyed more than CON both during and following the exercises. Participants were men and women $(n=14)$ between the age of 30-55 years with a BMI of $25-35 \mathrm{~kg} / \mathrm{m}^{2}$. Participants completed three exercise conditions: $\mathrm{CON}$ ) a 45 minute walk at $60 \%$ of age predicted maximal heart rate (APMHR), HIIT60) a 20 minute HIIT exercise in which the speed and incline was changed between a high intensity of 80\% APMHR and 60\% APMHR every 60 seconds for a total of 10 cycles, and HIIT90) a 21 minute HIIT exercise in which the speed and incline was changed between a high intensity of 80\% APMHR and 60\% APMHR every 90 seconds for a total of 7 cycles. Heart rate (HR), exercise enjoyment during the exercise as measured by the exercise enjoyment scale (EES), and ratings of perceived exertion (RPE) were collected at multiple time points during the exercise. Five minutes of post exercise oxygen consumption was measured immediately and 30 minutes following the exercise sessions. General feelings as measured by the feeling scale (FS) and physical activity (PA) enjoyment as measured by the physical activity enjoyment scale (PACES) was measured 5 minutes and 35 minutes following the exercise sessions. HR and RPE were both higher in HIIT60 and HIIT90 compared to CON. In task exercise enjoyment was not higher between conditions. PA enjoyment was higher in both HIIT60 and HIIT90 compared to CON 5 minutes following the exercises. General feelings in HIIT60 was the only condition to increase 35 minutes compared to 5 minutes following the exercise. We conclude that HIIT is a more preferred exercise than CON as shown by higher preferences for HIIT90 and HIIT60 as well as higher ratings of post exercise PA enjoyment.
\end{abstract}




\section{CHAPTER ONE}

\section{INTRODUCTION}

\section{Development of the Problem}

The current average diet and sedentary lifestyle is resulting in a rise of chronic

disease. ${ }^{1-3}$ An estimated 9.3 percent, or nearly 21 million American adults, are estimated to have diabetes. ${ }^{4}$ Projections for diabetes and prediabetes are expected to grow at much more alarming rates in the coming years. ${ }^{5}$ There is also an estimated 26.6 million Americans that are said to have cardiovascular disease (CVD). ${ }^{6}$ The prevalence of CVD is also expected to grow. ${ }^{7}$ It can be anticipated that $40.5 \%$ of the American population will have some form of CVD by the year 2030, if current lifestyle and healthcare efforts stay as status quo.

Chronic diseases result in reduced quality and longevity of life. For example, the rise in CVD prevalence will result in triple the total direct medical costs that are currently experienced. ${ }^{7}$ Regular physical activity, coupled with a healthy diet, may decrease the risk of morbidity and mortality among the leading causes of death. ${ }^{1-3}$

The American College of Sports Medicine (ACSM) currently recommends 30 minutes of moderate intensity aerobic exercise at least 5 days a week and strength training exercise at least two days a week. ${ }^{8}$ Currently, sedentary lifestyles are resulting in the rise of chronic disease as only $20.8 \%$ of Americans are currently reaching the ACSM physical activity recommendations. ${ }^{1-3,9}$ 
Exercise standards must be met in order to positively impact health outcomes for a population that is largely classified as sedentary. ${ }^{10}$ Contributors to a sedentary lifestyle include: prolonged sitting both at work and home as well as advances in technology which has led to increases in television viewing time and time sitting in cars. ${ }^{10} \mathrm{~A}$ sedentary lifestyle is very often linked to a lack of exercise adherence. ${ }^{11,12}$ Perceived lack of time to exercise and boredom during continuous aerobic exercise have contributed to the lack of exercise adherence. ${ }^{13-15}$

Time and cost effective exercise regimens would theoretically contribute to increased exercise adherence, decreased sedentary lifestyle, and allow for the best health outcomes among all populations. This exercise regimen would be one that is shorter in duration and decreases the amount of monotony experienced during exercise.

High intensity interval training (HIIT) has the potential ability to meet two of the major reasons for a lack of exercise adherence. High intensity interval training is a bout of exercise that integrates a near maximal intensity for a short period of time (30 seconds to 4 minutes), this is then followed by a bout of active recovery at a much lower intensity and started over again for multiple intervals. ${ }^{16}$ There is a possibility that HIIT has the ability to theoretically decrease the sensation of boredom experienced during exercise as the changes in intensity would decrease the experience of dullness. A decreased amount of time spent exercising would also decrease boredom as there would be less time spent for monotony to set in.

It has been demonstrated that HIIT is capable of providing equal to superior metabolic demands in comparison to continuous aerobic exercise with a shorter duration 
of demanded time. ${ }^{16-21}$ The majority of research concerning HIIT has examined the metabolic demands and health improvements experienced. ${ }^{16-21}$ Health improvements include increases in glucose transporter 4 (GLUT4), decreased body mass, increased mitochondrial density, decreased hip and waist circumference, and increased substrate utilization. $^{16,19,20,22,23}$

Participants of HIIT have also anecdotally reported that they prefer to take part in HIIT in comparison to continuous aerobic exercise. These anecdotal responses have led to the initial research regarding the preferences and perceptions of participating in bouts of HIIT. ${ }^{24-26}$ Observed preferences include superior enjoyment and affect during HIIT conditions lasting 30 seconds to 60 seconds. ${ }^{25,27,28}$

Current research has mainly observed the perceptual responses experienced among younger individuals (18-33 years). ${ }^{25,26,28}$ The majority of studies, regarding preferences and perceptions of HIIT, have also shown that there is a large interindividuality in terms of preferences and perceptions. ${ }^{25,26,28}$ The large inter-individuality would result in the need for a mixed methods approach in the hopes of gathering rich and contextualized data that identifies the overarching themes and trends within HIIT participants. More research is required in order to better understand the perceptual responses of HIIT among populations that are more at risk of metabolic conditions as exercise adherence tends to be low in these individuals. A better, more in depth understanding of the preferences of HIIT will help to better understand if HIIT is a realistic exercise regimen that would improve exercise adherence/compliance. 


\section{$\underline{\text { Purpose }}$}

The aim of this study was to analyze, through a mixed methods approach, whether participants prefer HIIT in comparison to continuous aerobic exercise. More specifically, the study observed feelings of enjoyment, ratings of perceived exertion, as well as exercise preferences both during and following exercise (qualitative publication forthcoming).

\section{$\underline{\text { Implications }}$}

The most significant long-term implication in this study is the potential to determine if HIIT is a preferred exercise intervention within the general population. This exercise intervention would theoretically allow for another option in which populations could take part in to increase physical activity as well as improve health outcomes. Therefore, it was necessary to analyze whether participants prefer to take part in HIIT, which has been shown to be an exercise intervention that has the ability to reduce visceral adipose tissue, improve cardiovascular function, improve glycemic control, and reduce the risks of morbidity and mortality related to metabolic syndrome and a lack of physical activity. ${ }^{21,29,30}$ This study will help to examine what participants prefer about HIIT and why they would prefer, or not prefer, to take part in a bout of HIIT in comparison to continuous aerobic exercise. An exercise intervention that participants prefer to take part in would be a much more ideal intervention to assure that exercise adherence is as high as possible. 
Future studies would then be able to analyze whether participants prefer HIIT over a long term exercise intervention if it is proven that preferences for HIIT are high through a single bout of HIIT.

\section{Hypotheses}

$\mathrm{H}_{1----} \mathrm{It}$ is hypothesized that participants would prefer to take part in HIIT rather than continuous aerobic exercise.

$\mathrm{H}_{2----}$ Valence, the positive or negative emotional response to an event, will be low while exercising at higher intensities but will increase following the commencement of the exercise bout.

$\mathrm{H}_{3}$---- Feelings of enjoyment will be higher following HIIT compared to continuous aerobic exercise.

\section{$\underline{\text { Research Questions }}$}

Q1---- How do overweight/obese individuals perceive HIIT in terms of exercise enjoyment, preferences, and exercise adherence?

Q2---- What are specific reasons that overweight/obese individuals either prefer of not prefer HIIT compared to continuous aerobic exercise?

\section{Operational Definitions}

Affect: A general valenced response (positive or negative) that does not require a higher level of thinking. 
Affective Valence: A positive or negative emotion, without the need for intuitive thinking that is brought on by an activity, event, object, or person.

Age Predicted Maximal Heart Rate: The estimated maximal heart rate based on an individual's current age.

Body Mass Index (BMI): A calculated value based on mass and height that is meant to classify an individual's body composition and weight status.

Continuous Aerobic Exercise: A moderate intensity exercise in which the exercise intensity remains constant throughout the exercise session.

Exercise Enjoyment Scale: A seven point likert scale meant for the analysis of exercise enjoyment.

Feeling Scale: An 11 point scale meant for the analysis of general feelings.

High Intensity Interval Training: an exercise session that integrates a near maximal intensity for a short period of time (30 seconds to 4 minutes), this is then followed by a bout of active recovery at a much lower intensity.

Moderately Obese: A BMI of 30-34.9 kg/m².

Overweight: A BMI of $25-29.9 \mathrm{~kg} / \mathrm{m}^{2}$.

Physical Activity Enjoyment Scale: An 18 question post exercise questionnaire meant for the analysis of physical activity enjoyment.

Ratings of Perceived Exertion: A 15 point scale meant for the analysis of current perceived physical exertion.

Valence: The positive or negative emotion towards an activity, event, object, or person. 
$\mathrm{VO}_{2 \max }$ : Maximal oxygen consumption as predicted by a graded submaximal exercise test.

\section{$\underline{\text { Abbreviations }}$}

BMI: Body Mass Index

Bpm: Heart beats per minutes.

CVD: Cardiovascular Disease

EES: Exercise Enjoyment Scale

FS: Feeling Scale

GLUT4: Glucose Transporter-4

HIIT: High Intensity Interval Training

HIIT60: High Intensity Interval Training for 60 seconds per repetition

HIIT90: High Intensity Interval Training for 90 seconds per repetition

HR: Heart Rate

PA: Physical Activity

PACES: Physical Activity Enjoyment Scale

RPE: Ratings of Perceived Exertion

\section{$\underline{\text { Delimitations }}$}

A primary delimitation of this study was characteristics of the participants. Only men and women between the age of 30 and 55 years old were recruited for this study. This study was also completed in a more rural town in the state of Montana. With that 
being said, all, but one, participant who chose to take part in the study were Caucasian individuals. A second delimitation is that participants were classified as overweight or obese as an inclusion criteria with a body mass index (BMI) of $25-35 \mathrm{~kg} / \mathrm{m}^{2}$. A third delimitation is that the study utilized acute bouts of HIIT rather than chronic uses of HIIT. The use of acute bouts of HIIT therefore do not allow for the understanding of HIIT preferences and perceptions when completed chronically.

\section{$\underline{\text { Limitations }}$}

One major limitation to the study was that the participants never took part in HIIT or took part in HIIT only a few times. The lack of familiarity with HIIT as well as the lack of familiarity with participating in an exercise study may have caused some unwanted stress and anxiety. The participants also exercised at intensities that were uncomfortable and challenging, which could have possibly clouded some of perceptions and preferences, and may change over time with prolonged participation in HIIT. Efforts were made to control the amount of stress and anxiety experienced during the exercise bouts. A second limitation was the use of only one indicator for exercise enjoyment while exercising. This is due to the lack of reasonable options while exercising during short term exercise intensities as well as a lack of time to collect data during each exercise cycle. A third limitation was the possibility that the participant's heart rate did not reach the ideal heart rate for the entire time of each repetition during HIIT. This may have resulted in the metabolic demands of HIIT not reaching the expected metabolic demands during the HIIT conditions. It is believed that the metabolic demands of HIIT following 
exercise would be superior to that of continuous aerobic exercise due to the higher intensity requirements and increased motor recruitment. This was analyzed through oxygen consumption measurements at different points 30 minutes following the exercise bouts. 


\section{CHAPTER TWO}

\section{LITERATURE REVIEW}

\section{$\underline{\text { Introduction }}$}

Obesity is one of the primary risk factors of cardiovascular disease, diabetes, and many other metabolic diseases. Sedentary behavior is one of the primary reasons for the development of obesity. ${ }^{11,12}$ Research regarding exercise adherence shows that a lack of perceived time to exercise and monotony during exercise are some of the main reasons that people choose not to take part in exercise bouts. ${ }^{13-15}$ There must be more research into finding more exercise regimens that participants, as a whole, prefer to take part in so that exercise adherence can be improved within the United States. It would be most ideal to offer an exercise bout that participants prefer to take part in and also challenges some of the main reasons for a lack of exercise adherence. ${ }^{6,7}$

\section{Lack of Time to Exercise}

The United States population often states that the main factor for a lack of exercise adherence is the lack of time available to exercise. ${ }^{13-15}$ The American College of Sports Medicine states that the general population should be taking part in 30 minutes of moderate to vigorous aerobic exercise most days of the week. ${ }^{31}$ With the busy lives led by the general American population, this can be perceived as extremely difficult to complete, especially when enjoyment during the bouts of exercise are low. High intensity interval training has begun to be implemented within the general population as a way to 
possibly engage those who perceive a lack of time as one of the major reasons for a lack of exercise adherence.

\section{High Intensity Interval Training}

High intensity interval training has been an exercise regimen that has seen much research and interest for the general population after largely being an exercise bout used by athletes. Woldemar Gerschler, a German track coach in the late 1930s, can largely be credited for implementing HIIT. ${ }^{32}$ Gerschler used HIIT as a way of training the cardiovascular system much like other muscles are trained. This training later led to many world championships and world records. ${ }^{32}$ This athletic training method was later used by Roger Bannister who was the first human to break the infamous four minute mile. ${ }^{33}$ However, traditional HIIT methods have led to feelings of nausea, lightheadedness, and discomfort for the general population. ${ }^{34}$ These issues have led to the need for a more practical, lower volume HIIT set in order to benefit adherence/compliance in the general population while still leading to comparable metabolic and physiological improvements.

\section{Practical Low-Volume High Intensity Interval Training}

Little and colleagues developed a more practical low-volume HIIT method with the intentions of preserving the health benefits and time efficiency while addressing problems with adherence and compliance. ${ }^{16}$ Practical low-volume HIIT has been shown to have comparable metabolic demands as well as metabolic improvements to continuous aerobic training. ${ }^{21,29}$ For example, it has been demonstrated that HIIT can be an ideal 
option for improving cardiovascular function within patients with CVD. ${ }^{21,29}$ Practical Low-Volume HIIT prescribes intensities based on the maximal aerobic capacity of the participant which is measured using maximal oxygen consumption $\left(\mathrm{VO}_{2 \max }\right)$ Prescribing exercise intensities based on $\mathrm{VO}_{2 \max }$ tests then results in more tolerable exercise intensities. Generally, practical low-volume HIIT is comprised of shorter durations at each cycle of around 60 seconds to two minutes. The total exercise bout, excluding warm-up and cool-down lasts around 20 minutes. ${ }^{16}$

Table 2.1: Significant HIIT studies with protocols, participants, interventions, and significant outcomes.

\begin{tabular}{|c|c|c|c|c|}
\hline Study & HIIT Protocol & $\begin{array}{l}\text { Research } \\
\text { Population }\end{array}$ & Intervention & $\begin{array}{c}\text { Main } \\
\text { Outcomes }\end{array}$ \\
\hline $\begin{array}{c}\text { Bartlett et } \\
\text { al. }^{27}\end{array}$ & $\begin{array}{c}\text { HIIT: } 6 \text { intervals, } 3 \\
\text { min } 90 \% \mathrm{VO}_{2 \max } / 3 \\
\min 50 \% \mathrm{VO}_{2 \max } \\
\text { END: } 50 \text { min } 70 \% \\
\mathrm{VO}_{2 \max }\end{array}$ & $\begin{array}{l}8 \text { recreationally } \\
\text { active men }\end{array}$ & HIIT vs. END & $\begin{array}{c}\uparrow \text { HIIT } \\
\text { enjoyment, } \uparrow \\
\text { HIIT RPE, }\end{array}$ \\
\hline Greeley $^{28}$ & $\begin{array}{c}\text { CM: } 20 \text { min } 20 \% \\
\downarrow \text { VT. } \\
\text { CH: } 20 \text { min @ VT. } \\
\text { IH: } 10 \text { intervals, 60 } \\
\text { sec @ VT/60 sec } \\
\text { rec. } \\
\text { IS: } 10 \text { intervals, } 60 \\
\text { sec } 20 \% \uparrow \text { VT/60 } \\
\text { sec rec. }\end{array}$ & $\begin{array}{c}10 \text { participants, } \\
21.6 \text { yo }\end{array}$ & $\begin{array}{c}\text { CM vs. CH vs. } \\
\text { IH vs. IS }\end{array}$ & $\begin{array}{c}\uparrow \mathrm{CM} \& \mathrm{IH} \\
\text { enjoyment and } \\
\text { affect }\end{array}$ \\
\hline
\end{tabular}


Table 2.1 - CONTINUED:

\begin{tabular}{|c|c|c|c|c|}
\hline $\begin{array}{l}\text { Little et } \\
\text { al. }{ }^{16}\end{array}$ & $\begin{array}{c}10 \text { intervals, } 60 \\
\text { sec } 90 \% \\
\mathrm{HR}_{\max } / 60 \mathrm{sec} \\
50 \mathrm{~W}\end{array}$ & $\begin{array}{c}8 \text { participants w/ } \\
\text { T2D, } 62.5 \text { yo }\end{array}$ & $\begin{array}{l}6 \text { sessions over } \\
2 \text { weeks }\end{array}$ & $\begin{array}{c}\downarrow \text { Ave } 24 \mathrm{hr} \text { [glu] } \\
\downarrow 3 \mathrm{hr} \text { [glu] AUC, } \uparrow \\
\text { mitochondrial } \\
\text { capacity and } \\
\text { GLUT4 }\end{array}$ \\
\hline $\begin{array}{l}\text { Little et } \\
\text { al. }{ }^{35}\end{array}$ & $\begin{array}{c}\text { 8-10 } \\
\text { intervals,60 sec } \\
\text { PPO/75 sec } \\
\text { 30W }\end{array}$ & $\begin{array}{l}7 \text { men, } \\
\text { recreationally } \\
\text { active, } 21 \text { yo }\end{array}$ & $\begin{array}{c}6 \text { sessions over } \\
2 \text { weeks }\end{array}$ & $\begin{array}{l}\uparrow \text { resting muscle } \\
\text { glycogen and } \\
\text { GLUT4, } \uparrow \\
\text { exercise capacity }\end{array}$ \\
\hline Martinez $^{25}$ & $\begin{array}{c}\text { CH: } 20 \mathrm{~min}, \\
\text { 10\% DT. } \\
\text { IS30: } 24 \\
\text { intervals, } 30 \mathrm{sec} \\
\text { 60\%DT/30 sec } \\
\text { rec. } \\
\text { IS60: } 12 \\
\text { intervals, } 60 \mathrm{sec} \\
\text { 60\%DT/60 sec } \\
\text { rec. }\end{array}$ & $\begin{array}{c}14 \mathrm{OW} \\
\text { sedentary } \\
\text { participants }\end{array}$ & $\begin{array}{l}\text { CH vs IS30 vs } \\
\text { IS60 vs IS120 }\end{array}$ & $\begin{array}{l}\uparrow \text { IS30 \& IS60 in } \\
\text { task affect \& } \\
\text { enjoyment. }\end{array}$ \\
\hline $\begin{array}{l}\text { Racil et } \\
\text { al. }{ }^{19}\end{array}$ & $\begin{array}{c}\text { CON: No } \\
\text { exercise } \\
\text { HIIT: } 6 \\
\text { intervals, } 30 \mathrm{sec} \\
\text { 100-110\% max } \\
\text { speed/30 sec } \\
\text { 50\% max speed. } \\
\text { MIIT: } 6 \\
\text { intervals, } 30 \text { sec } \\
70 \% \text { max } \\
\text { speed/ } 30 \text { sec } \\
50 \% \text { max speed }\end{array}$ & $\begin{array}{c}34 \text { OB } \\
\text { adolescents, } \\
15.9 \text { yo }\end{array}$ & $\begin{array}{c}24 \text { sessions } \\
\text { over } 12 \text { weeks }\end{array}$ & $\begin{array}{c}\downarrow \text { BM, BMI, FM\%, } \\
\downarrow \text { LDL-C, } \uparrow \text { HDL- } \\
\text { C, } \uparrow \text { adiponectin, } \\
\downarrow \text { waist circ., TG, } \\
\text { TC }\end{array}$ \\
\hline
\end{tabular}


Table 2.1 - CONTINUED

\begin{tabular}{|c|c|c|c|c|}
\hline $\begin{array}{l}\text { Whyte } \\
\text { et al. }\end{array}$ & $\begin{array}{c}6 \text { intervals, } 30 \\
\text { sec “all out”/4.5 } \\
\text { min recovery }\end{array}$ & $\begin{array}{c}10 \text { OW/OB } \\
\text { sedentary men, } \\
32.1 \text { yo }\end{array}$ & $\begin{array}{c}6 \text { sessions over } \\
2 \text { weeks }\end{array}$ & $\begin{array}{c}\uparrow \text { HOMA-IR, } \uparrow \\
\text { resting fat oxid., } \downarrow \\
\text { resting CHO oxid., } \downarrow \\
\text { waist and hip circ. }\end{array}$ \\
\hline
\end{tabular}

CON: continuous aerobic training; END: endurance training; HIIT: high intensity interval training; MIIT: moderate intensity interval training; CM: continuous moderate; $\mathrm{CH}$ : continuous heavy; IS30: interval sprint for 30 seconds; IS60: interval sprint for 60 seconds; PPO: peak power output; DT: delta of intensities; VT: ventilatory threshold; T2D: type 2 diabetes; OW/OB: overweight and obese; OW: overweight; [glu]: blood glucose concentrations; [glu] AUC: blood glucose concentration area under the curve; GLUT4: glucose transporter-4; HOMA-IR: homesostatic model assessment for insulin resistance; BM: body mass; BMI: body mass index; FM\%: fat mass percentage; LDL-C: low density lipoprotein cholesterol; HDL-C: high density lipoprotein cholesterol; TG: triglycerides; TC: total cholesterol

\section{$\underline{\text { Metabolic Improvements }}$}

Significant metabolic improvements have been shown following exercise interventions involving HIIT. Postprandial hyperglycemia has been shown to improve in individuals with, or at risk for, type 2 diabetes when HIIT is implemented. ${ }^{20}$ Mechanisms for postprandial hyperglycemia improvements have largely been attributed to the fact that skeletal muscle is responsible for the majority of glucose disposal following the ingestion of a meal. ${ }^{37}$ There has also been a demonstrated ability to improve metabolic function as the exercise bout has the ability to promote a higher level of muscle fiber recruitment, increase the depletion of muscle glycogen, and promote a greater response in skeletal muscle glucose transport-4 (GLUT4) when HIIT is implemented. ${ }^{20,38-40}$ Average glucose concentrations, 24 hours, post HIIT and glucose area under the curve following subsequent meals have been shown to be improved in comparison to average glucose concentrations following continuous aerobic exercise. ${ }^{16}$ Mitochondrial capacity as well as 
GLUT4 activity has been demonstrated to improve following HIIT. ${ }^{16}$ Postprandial glucose area under the curve, postprandial peak glucose concentrations, and average blood glucose concentrations 60-120 minutes following a meal have also been shown to be improved following single bouts of HIIT. ${ }^{30}$ These studies indicate that HIIT has the ability to improve glycemic control in individuals with, or at risk for, type 2 diabetes for a number of reasons including greater muscle recruitment and greater depletion of muscle glycogen. ${ }^{38,39}$ Metabolic outcomes have varied across interventions as HIIT dosage has varied as well.

Other metabolic factors including substrate utilization and blood pressure have been shown to improve following HIIT. ${ }^{22}$ Both acute and chronic HIIT training, in overweight and obese sedentary men, have been shown to lead to an improvement in increased fat oxidation and decreased carbohydrate oxidation in the rested state. ${ }^{22,36}$ Chronic HIIT training also has been shown to have the ability to improve lipid and adiponectin levels in individuals who are overweight/obese. ${ }^{19,41}$

\section{$\underline{\text { Body Composition Improvements }}$}

High intensity interval training has been shown to lead to significant improvements in body composition when subjecting participants to longer termed HIIT interventions. ${ }^{18,42,43}$ Tremblay and colleagues subjected participants to either 24 weeks of HIIT or 24 weeks of continuous aerobic exercise. ${ }^{42}$ Following the 24 weeks of exercise intervention, it was found that the HIIT group lost significantly more subcutaneous fat than the continuous aerobic training group. Similarly, Trapp and colleagues also 
subjected participants to long term HIIT versus long term continuous aerobic exercise and found that the HIIT group lost significantly more subcutaneous fat as well as abdominal fat. ${ }^{43}$ Visceral adipose tissue loss has also been seen following long term HIIT interventions. ${ }^{44,45}$ Improvements in body composition can also be seen through improvements in waist and hip circumference following long term HIIT interventions. $^{19,36}$

\section{$\underline{\text { Cardiovascular Improvements }}$}

High intensity interval training has been shown to have beneficial effects within individuals with CVD and decreased cardiovascular function. ${ }^{21,29,46}$ Much like metabolic improvements from HIIT, there is varying effects of HIIT on cardiovascular function as dosage and intensity varies within different studies. Implementation of HIIT has begun within cardiac rehabilitation facilities, resulting in beneficial outcomes. ${ }^{46}$ Therefore, HIIT may also be beneficial for populations with metabolic syndromes with minimal adverse effects.

Longitudinal HIIT has been shown to have improved effects on blood pressure in individuals with metabolic disease. ${ }^{36}$ Improved cardiovascular function has largely been debated which likely can be attributed to differences in exercise dosage as well as intensity and exercise modes. Improved cardiorespiratory fitness, in individuals with CVD, has been demonstrated with improvements in $\mathrm{VO}_{2 p e a k}$ following $\mathrm{HIIT}^{21,29}$

It has been demonstrated that HIIT provides beneficial improvements in the blood ejection of the heart. ${ }^{21,29}$ Left ventricular diastolic and systolic volumes has been shown following HIIT and left ventricular fraction.${ }^{29}$ Brachial artery flow has the ability to 
improve with long term HIIT training as well. ${ }^{21}$ These cardiovascular improvements, as a result of HIIT, have been shown to result in a decrease in New York Heart Association

disease classification as well as improved quality of life within individuals with CVD. ${ }^{21,29}$ These findings also demonstrate that HIIT has the ability to be both safe and functional in improving cardiorespiratory fitness and cardiovascular function in individuals with a multitude of cardiovascular diseases.

\section{Feelings of Enjoyment Assessments}

Researchers investigating perceptions and feelings of enjoyment during and following exercise have focused on exercise enjoyment in order to better understand how exercise adherence will be affected during different exercise bouts. Multiple assessment tools have been implemented in order to characterize the specific exercise perceptions related to enjoyment and adherence.

The Physical Activity Enjoyment Scale is an exercise enjoyment questionnaire consisting of 18 questions. ${ }^{47}$ The questionnaire begins with the statement, "Please rate how you feel at this moment about the exercise you have been doing by circling the number that seems most appropriate.” There is a seven point likert scale within each question. Examples of choices include: I enjoy it/I hate it, I feel good physically while doing it/I feel bad physically while doing it, and it's not at all stimulating/it's very stimulating. The Physical Activity Enjoyment Scale has been an exercise enjoyment questionnaire used during many different exercise enjoyment studies. ${ }^{22,24,29,30}$ Normative 
and validation data regarding Physical Activity Enjoyment Scale can be found with Kendzierski \& DeCarlo, $1991 .{ }^{47}$

The Feeling Scale is another exercise feeling scale that has also been used for exercise perception assessment. ${ }^{50,51}$ This questionnaire is an 11-point questionnaire ranging from +5 (very good) to -5 (very bad). The questionnaire begins with the statement, "Please rate how you currently feel.” This questionnaire has been used in many different exercise enjoyment studies as a way of measuring exercise affect. ${ }^{50-53}$

The Exercise Enjoyment Scale is an exercise enjoyment questionnaire that has largely been used for the measurement of exercise enjoyment during the exercise session. ${ }^{54,55}$ This questionnaire begins with the statement, "Use the following scale to indicate how much you are enjoying this exercise session.” The questionnaire is a 7 point likert scale with anchors at every integer from 1 to 7 , ranging from "not at all" at 1 to “extremely” at $7 . .^{54,55}$

\section{Solomon's Opponent Process Theory}

Solomon’s Opponent Process Theory provides the model for post exercise affect. ${ }^{56}$ Solomon proposed that there is a pleasure or displeasure experienced during events which is referred to as the a-process. The a-process results in either a pleasure or displeasure affective response experienced during the event. ${ }^{56}$ In terms of exercise, the aprocess would be experienced during the exercise bout itself. This affective response would either increase or decrease away from a baseline affect. Solomon theorized that there would be a gradual return to baseline affect, starting immediately after the 
termination of the event. The return to baseline is referred to as the b-process. This process is the opposite response as the a-process. ${ }^{56}$ In terms of exercise, the b-process would either increase or decrease back to a baseline affect at the termination of the exercise bout.

Ekkekakis later expanded on Solomon's theory in relation to exercise affective valence. ${ }^{57}$ Ekkekakis states that the a-process, experienced by the exerciser, is displeasure during the exercise bout when the intensity is above the individual's ventilatory threshold. ${ }^{57}$ The ventilatory threshold, in the average population, takes place around 50$75 \%$ of the individual's $\mathrm{VO}_{2 \max }{ }^{58}$ It is theorized that the individual will then experience a return to a baseline affect when the exercise bout is complete. ${ }^{57}$

\section{Perceptual Responses to HIIT}

Emerging research investigates reasons that the majority of the population perceives HIIT which has a proven physiological benefit. ${ }^{24,25,28,55}$ Investigators are analyzing the perceptual responses of HIIT as a way of determining if HIIT is an exercise bout that the general population would prefer to take part in.

The perceptual responses to HIIT have been examined using different populations including sedentary and overweight or obese as well as young and active individuals. ${ }^{24,25,28}$ These investigators have all used intensities above ventilatory threshold during the high intensity repetitions. Exercise intensities have been measured using percentage of ventilatory threshold, percentage of heart rate maximum, as well as work

rate when a cycle ergometer is used as an exercise mode. ${ }^{24,25,28}$ Investigators have varied 
the dosage of the given repetitions as well. These repetition dosages have ranged from 30 seconds to 2 minutes. ${ }^{24,25,28,55}$ These HIIT protocols generally last for around 20 minutes in totality. ${ }^{24,25,28,55}$

It has been shown that exercise enjoyment during the exercise session and affective valence is higher in repetitions lasting 30-60 seconds. ${ }^{24,25,55}$ However, the exercise stimulus does not seem to elicit enough of a physiological stress, during the repetitions lasting less than 60 seconds, based on recorded heart rates during the exercise session and ratings of perceived exertion (RPE). ${ }^{25}$ These favorable enjoyment and affective valences have also been shown during intensities that are closer to ventilatory threshold rather than intensities that tend to be significantly higher than ventilatory threshold. ${ }^{25,28}$ Ratings of Perceived Exertion is higher during HIIT in comparison to continuous aerobic exercise. ${ }^{25,28}$ However, this does not seem to affect enjoyment and valence within HIIT. Exercise enjoyment during the exercise and affect has been shown to be significantly lower in repetitions lasting 2 minutes. $^{25,28}$

Responses to HIIT perceptions have shown that there is a high inter individual variability. ${ }^{25}$ This high inter individual variability has been found in solely quantitative studies. This shows that there is a need for a mixed methods approach to find trends and themes of HIIT perceptions that solely quantitative research may not be reaching.

\section{$\underline{\text { Summary }}$}

Exercise adherence/compliance appears to be low, within the general population, for a number of reasons including perceived lack of time and boredom. High intensity 
interval training, which was originally designed for athletic performance training, has been thought to be an exercise intervention that could be used to improve exercise adherence.

Traditional HIIT has led to side effects of nausea, lightheadedness, and discomfort, while exercising, which has led to the implementation of practical lowvolume HIIT. Practical low-volume HIIT has been shown to have metabolic improvements including improved glycemic control as well as substrate utilization. Practical low-volume HIIT has also been shown to lead to improved body composition as well as cardiovascular function.

Practical low-volume HIIT is beginning to be examined for perceptual and preferential responses in comparison to continuous aerobic exercise. These comparisons are meant to better understand if the theoretically preferred aspects of HIIT will lead to improved exercise adherence within the general population. It has been found that exercise enjoyment is higher in practical low-volume HIIT. However, it has been stated that there is a high inter-individual variability within HIIT perceptions. This has led to the need for a mixed methods research design in order to better understand the themes and responses to HIIT and how the responses and themes may lead to improved exercise adherence. 
CHAPTER THREE

\title{
PERCEPTUAL RESPONSES TO HIGH INTENSITY INTERVAL TRAINING AMONG OVERWEIGHT AND OBESE INDIVIDUALS
}

\author{
$\underline{\text { Contribution of Authors and Co-Authors }}$
}

Manuscript in Chapter 3

Author: John Halvorson

Contributions: Conceived and implemented the study design. Collected and analyzed data. Ran the statistical analyses. Wrote the first draft of the manuscript.

Co-Author: Mary Miles, PhD

Contributions: Conceived and implemented the study design. Provided expertise and funding. Aided in statistical and data analyses. Provided feedback on the draft of the manuscript.

Co-Author: Carmen Byker -Shanks, PhD

Contributions: Conceived and implemented the study design. Provided qualitative analysis expertise. Aided in qualitative data analysis.

Co-Author: John Seifert, PhD

Contributions: Provided quantitative analysis expertise. Provided quantitative statistical analysis expertise. 
Manuscript Information Page

John T Halvorson, Mary P Miles, Carmen Byker -Shanks, John Seifert

Status of Manuscript:

_X_ Prepared for submission to a peer-reviewed journal Officially submitted to a peer-review journal

Accepted by a peer-review journal

Published in a peer-review journal 


\section{PERCEPTUAL RESPONSES TO HIGH INTENSITY INTERVAL TRAINING AMONG OVERWEIGHT AND OBESE INDIVIDUALS}

\section{$\underline{\text { Introduction }}$}

Obesity, chronic disease, and metabolic syndrome continue to rise within the United States and the world largely as a result of poor diet and sedentary lifestyles. ${ }^{1-3}$ An estimated 9.3 percent of the American population is said to currently have diabetes in which the projections are expected to grow if medical care and lifestyle standards stay status quo. ${ }^{4,5}$ Currently, 26.6 million Americans are known to have cardiovascular disease and the projections are also expected to rise if health and lifestyle standards remain at current levels. ${ }^{6,59}$

Regular physical activity and a healthy diet have been shown to decrease the risk of morbidity and mortality for chronic diseases such as type 2 diabetes, cardiovascular disease, stroke, and cancer. ${ }^{1-3}$ Exercise standards must be met in order to decrease the risk of morbidity and mortality that is associated with poor diet and exercise standards. ${ }^{10}$

Poor physical activity can largely be associated with poor exercise adherence in which perceived lack of time and boredom during exercise are known to be leading contributors. ${ }^{12,14,15,60,61}$ A time efficient and cost effective exercise regimen that individuals prefer to take part in has the possibility to combat a perceived lack of time and boredom during exercise would be the most advantageous exercise option.

High intensity interval training (HIIT) is an exercise form that has the theoretical potential to combat a perceived lack of time to exercise as well as boredom during 
exercise. HIIT is an exercise bout that incorporates a near maximal intensity for a short period of time (30 seconds to 4 minutes), followed by a bout of active recovery at a much lower intensity. ${ }^{16}$ HIIT has been shown to have equal to superior physiological and metabolic improvements in comparison to continuous aerobic exercise. ${ }^{16-21}$ HIIT takes significantly less time for equal physiological demands when compared to continuous aerobic exercise.

Perceptions of HIIT must be evaluated to better understand if HIIT will result in improved exercise adherence and possibly decrease the risk of morbidity and mortality associated with a sedentary lifestyle. The purpose of this investigation was to analyze whether participants prefer HIIT in comparison to continuous aerobic exercise through feelings of enjoyment, ratings of perceived exertion (RPE), as well as exercise preferences both during and following exercise.

\section{$\underline{\text { Methods }}$}

\section{$\underline{\text { Participants }}$}

Both men and women between the ages of 30 to 55 years old were recruited. These participants were recruited through fliers, emails, and announcements. Potential experiment participants were excluded from the study if they had a known health condition, lower body musculoskeletal limitations, heart disease, renal complications, or any other condition that is contraindicated to participate in a high intensity exercise study. Exclusion criteria included a body mass index less than $25 \mathrm{~kg} / \mathrm{m}^{2}$ or more than $35 \mathrm{~kg} / \mathrm{m}^{2}$, less than 30 years old or more than 55 years old, a body fat percentage of less than 20\%, 
and not fitting the criteria for exercise participation according to the American Heart Association/American College of Sports Medicine (AHA/ACSM) Health/Fitness Facility Pre-participation Screening Questionnaire (APPENDIX A). ${ }^{62}$

\section{$\underline{\text { Research Design }}$}

The research design consisted of a convergent parallel mixed methods approach. Participants were used as their own control. There were three exercise conditions in which responses during and following exercise were analyzed. The exercise conditions were prescribed in a randomized order for each participant. The exercise independent variables included: continuous aerobic walking, HIIT for 60 seconds per repetition (HIIT60), and HIIT for 90 seconds per repetition (HIIT90). The quantitative, dependent variables included: participant age, height, weight, body mass index (BMI), waist circumference, hip circumference, waist to hip ratio, body fat percentage, fat free mass percentage, and visceral adipose tissue, RPE during multiple time points of the exercise bouts, exercise enjoyment during the exercise sessions at multiple time points of the exercise bouts, post exercise feelings at two separate time points following exercise, post exercise physical activity enjoyment at two separate time points following the exercise, and oxygen consumption at two separate time points following the exercise.

\section{$\underline{\text { Informed Consent }}$}

The informed consent, which was approved by the Montana State University Human Institutional Review Board committee, was reviewed and signed at visit 1 (APPENDIX B). 


\section{$\underline{\text { Participant Characteristics }}$}

Participants visited the laboratory in which ample time was provided for a thorough overview of the study and any questions to be answered. Consent was then given, incentive for participation was in the form of ten dollars per exercise visit. The participant was asked not to eat or drink anything at least four hour prior to the visit. The participant was then asked to review the AHA/ACSM Health/Fitness Facility Preparticipation Screening Questionnaire to assure that all medical conditions were accounted for. Participants answered a questionnaire regarding their physical activity over the last seven days. Resting blood pressure was then measured and recorded (Omron Digital Blood Pressure Monitor, INTELLISCENSE). Height was measured using a stadiometer (Perspective Enterprises). Body composition was then measured by air displacement plethysmography and bioelectrical impedance (Bodpod Gold, COSMED; Seca514, SECA). Waist circumference was measured as the narrowest part of the torso between the xiphoid process and umbilicus. ${ }^{63}$ Hip circumference was measured at the widest part of buttocks at the level of the greater trochanter. ${ }^{63}$ Three measurements were taken, the values were reevaluated if the measurements were more than two centimeters apart. The measurements were then averaged. A modified Bruce protocol was then conducted on a treadmill (PPS55, Woodway, Waukesha, WI). The intensity of the test was increased every three minutes by altering the speed and incline until $85 \%$ of agepredicted maximal heart rate was reached. Age-predicted maximal heart rate was calculated using the Tanaka equation (208-0.7*age in years). ${ }^{62}$ Heart rate was recorded

throughout the test (Wearlink + Coded transmitter 31, Polar, Kempele, Finland). Oxygen 
consumption was measured throughout the test in which the participant ventilated through a mouthpiece and wore a nose clip; metabolic data was collected through a gas measurement system (TrueOne 2400, ParvoMedics, Sandy, UT).

\section{$\underline{\text { HIIT Practice Sessions }}$}

The participants then visited the laboratory to complete a HIIT practice session which was used to determine the necessary intensities and practice 5 cycles of HIIT60. The participant completed a five minute warm up at a speed of 2.5 miles per hour (mph) and a grade of $0 \%$ on the treadmill. Following the five minute warm up, the participant was subjected to a speed and incline that elicited $60 \%$ of the age predicted maximal heart rate, followed by a speed and incline that elicited $80 \%$ of the age predicted maximal heart rate. RPE was recorded just before the exercise intensity was lowered (APPENDIX C). The participant then walked at a speed of $2.5 \mathrm{mph}$ and $0 \%$ grade to lower heart rate. The participant then completed 5 HIIT60 cycles to assure that the intensities were appropriate and the participant was as comfortable as possible with the HIIT protocol. 


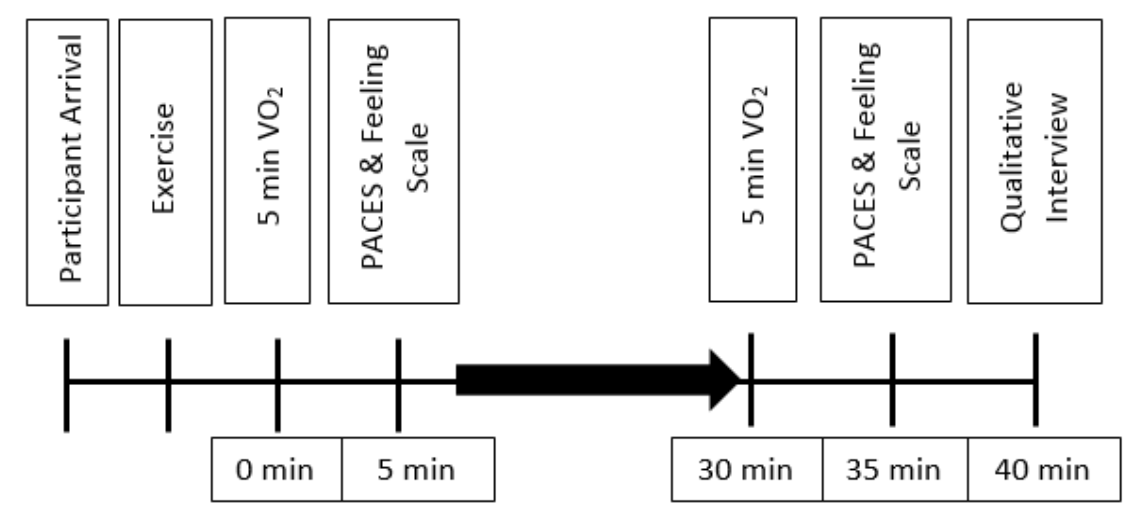

Figure 3.1 Design of the exercise visits. Visits 3,4, and 5 were randomized between continuous aerobic training, high intensity interval training 60 (HIIT60), and high intensity interval training 90 (HITT9).

\section{Continuous Aerobic Exercise}

The participants were asked to not consume any food or drink at least four hours prior to the exercise bout, and all other exercise bouts, to assure that no gastric discomfort would affect perceptions of the exercise. Upon arrival, the participants were fitted for a heart rate monitor. The participants then completed a 5 minute warm up, on the treadmill, at a speed of $2.5 \mathrm{mph}$ and $0 \%$ grade. The participants then walked for 45 minutes at a speed and incline that elicited $60 \%$ of the participant's age predicted maximal heart rate. Every three minutes, the participants were asked to assess their RPE and EES (APPENDIX D). Heart rate was also recorded every three minutes. A five minute cool down at a speed of $2.5 \mathrm{mph}$ and $0 \%$ grade was then completed following the 45 minutes.

\section{High Intensity Interval Training 60 (HIIT60)}

The participants were asked to not consume any food or drink at least four hours prior to the exercise bout, and all other exercise bouts, to assure that no gastric discomfort 
would affect perceptions of the exercise. Upon arrival to the laboratory, the participants were fitted for a heart rate monitor and began a treadmill warm up at a speed of $2.5 \mathrm{mph}$ and $0 \%$ grade. The participants then walked or ran at a speed and incline which elicited $80 \%$ of the age predicted maximal heart rate for 60 seconds. The participants then immediately walked or jogged at a speed and incline that elicited $60 \%$ of the age predicted maximal heart rate for 60 seconds. The high intensity followed by a low intensity equated to one cycle; ten cycles in total were completed. At the end of each 60 second repetition, the participants were asked to assess their current RPE and exercise enjoyment using the EES. Heart rate was also recorded at the end of each 60 second repetition. The participants then walked a five minute cool down at a speed of $2.5 \mathrm{mph}$ and $0 \%$ grade.

\section{High Intensity Interval Training 90 (HIIT90)}

The participants were asked to not consume any food or drink at least four hours prior to the exercise bout, and all other exercise bouts, to assure that no gastric discomfort would affect perceptions of the exercise. Upon arrival to the laboratory, the participants were fitted for a heart rate monitor and began a treadmill warm up at a speed of $2.5 \mathrm{mph}$ and $0 \%$ grade. The participants then walked or ran at a speed and incline which elicited $80 \%$ of the age predicted maximal heart rate for 90 seconds. The participants then immediately walked or jogged at a speed and incline that elicited $60 \%$ of the age predicted maximal heart rate for 90 seconds. The high intensity followed by a low intensity equated to one cycle; seven cycles in total were completed. At the end of each 60 second repetition, the participants were asked to assess their current RPE and exercise 
enjoyment using the EES. Heart rate was also recorded at the end of each 90 second repetition. The participants then walked a five minute cool down at a speed of $2.5 \mathrm{mph}$ and $0 \%$ grade.

\section{$\underline{\text { Post Exercise Assessments }}$}

Immediately following the cool down of continuous aerobic training, HIIT60, and HIIT90, the participants sat next to the treadmill in which oxygen consumption was measured for 5 minutes. The participants were then asked to complete a feelings scale (FS) (APPENDIX E) and physical activity enjoyment scale (PACES) questionnaire (APPENDIX F). 30 minutes following the exercise bout, the participants sat next to the treadmill for five minutes of oxygen consumption measurement. A FS and PACES questionnaire was then completed immediately following the five minute oxygen consumption measurement. The participants were also asked to rank the three exercise conditions from most preferred (1) to least preferred (3) following the final exercise condition (APPENDIX G).

\section{$\underline{\text { Statistical Analysis }}$}

For each group, means were calculated. A 3x2 repeated measures ANOVA and a Bonferroni's post hoc analysis was performed for the average heart rates at both the high and low intensity of the exercises as well as the average oxygen consumption both immediately and 30 minutes following the exercise conditions. Friedman nonparametric tests were performed for RPE during the exercises, EES during the exercises, FS 
following the exercises, PACES following the exercises, and the preference order of the three conditions.

\section{$\underline{\text { Results }}$}

\section{$\underline{\text { Participants }}$}

Anthropometric and physical activity characteristics for the participants are presented in Table 3.1. Participants can be characterized as overweight and obese adults who are currently healthy, untrained in HIIT, and sedentary.

Table 3.1 Characteristics of participants

\begin{tabular}{lll}
\hline \multicolumn{1}{c}{ Variable } & $\begin{array}{l}\text { Males }(\mathrm{N}=8) \\
(\text { Mean }+\mathrm{SD})\end{array}$ & $\begin{array}{l}\text { Females (N=6) } \\
(\text { Mean }+ \text { SD) }\end{array}$ \\
\hline Age (Years) & $31.4 \pm 10.3$ & $43.8 \pm 8.9$ \\
Height (cm) & $179.5 \pm 6.1$ & $162.0 \pm 5.6$ \\
Body Mass (kg) & $98.9 \pm 6.8$ & $75.5 \pm 4.8$ \\
BMI (kg/m²) & $30.6 \pm 2.6$ & $28.9 \pm 3.4$ \\
Waist Circumference (cm) & $99.6 \pm 4.8$ & $86.1 \pm 8.8$ \\
Hip Circumference (cm) & $108.7 \pm 5.0$ & $108.8 \pm 4.4$ \\
Waist to Hip Ratio & $0.9 \pm 0.1$ & $0.8 \pm 0.1$ \\
Body Fat \% & $28.5 \pm 4.6$ & $37.0 \pm 8.3$ \\
Fat Free Mass \% & $71.5 \pm 4.6$ & $63.0 \pm 8.3$ \\
Visceral Adipose Tissue (L) & $3.1 \pm 0.6$ & $1.7 \pm 1.2$ \\
VO 2 max (mL/kg/min) & $44.3 \pm 6.8$ & $36.8 \pm 12.4$ \\
Physical Activity (PA) Questionnaire & & \\
\multicolumn{1}{c}{ d/wk $>$ 30 minutes PA } & $3.6 \pm 1.5$ & $3.3 \pm 2.1$ \\
d/wk of muscular exercises & $2.4 \pm 1.9$ & $2.3 \pm 2.5$ \\
d/wk of stretching exercises & $3.3 \pm 1.8$ & \\
\hline
\end{tabular}




\section{Exercise Requirements}

Heart rates during the exercise are presented in Table 3.2 and Figure 3.2 in which there was a condition by time interaction. Heart rates during the exercise were significantly higher during HIIT60 and HIIT90 when compared to the continuous aerobic exercise $(\mathrm{p}<0.05)$. There were significant differences when comparing between conditions as well. Both HIIT90 and HIIT60 had significantly higher HR values at both the odd time points which are the high intensity cycles and the even time points which are the low intensity cycles $(\mathrm{p}<0.05)$. HIIT90 also had higher HR values compared to HIIT60 at the high intensity cycles and the low intensity cycles $(\mathrm{p}<0.05)$.

Table 3.2 Average heart rates during the exercise

\begin{tabular}{lll}
\hline Variable & $\begin{array}{l}\text { High Interval HR } \\
(\mathrm{M} \pm \mathrm{SD}) \\
\mathrm{N}=14\end{array}$ & $\begin{array}{l}\text { Low Interval HR } \\
(\mathrm{M} \pm \mathrm{SD}) \\
\mathrm{N}=14\end{array}$ \\
\hline Continuous Average Heart Rates (bpm) & $109.7 \pm 1.1$ & $109.0 \pm 1.8$ \\
HIIT60 Average Heart Rates (bpm) & $142.9 \pm 4.8^{\mathrm{ac}}$ & $122.9 \pm 4.9^{\mathrm{a}}$ \\
HIIT90 Average Heart Rates (bpm) & $148.4 \pm 3.7^{\mathrm{abc}}$ & $120.7 \pm 3.9^{\mathrm{a}}$ \\
\hline
\end{tabular}

* High interval HR=odd time point HR; low interval $\mathrm{HR}=$ even time point $\mathrm{HR}$

a $p<0.001$ compared to continuous

b $p<0.01$ compared to HIIT60

с $p<0.001$ 
Average HR at each Time point

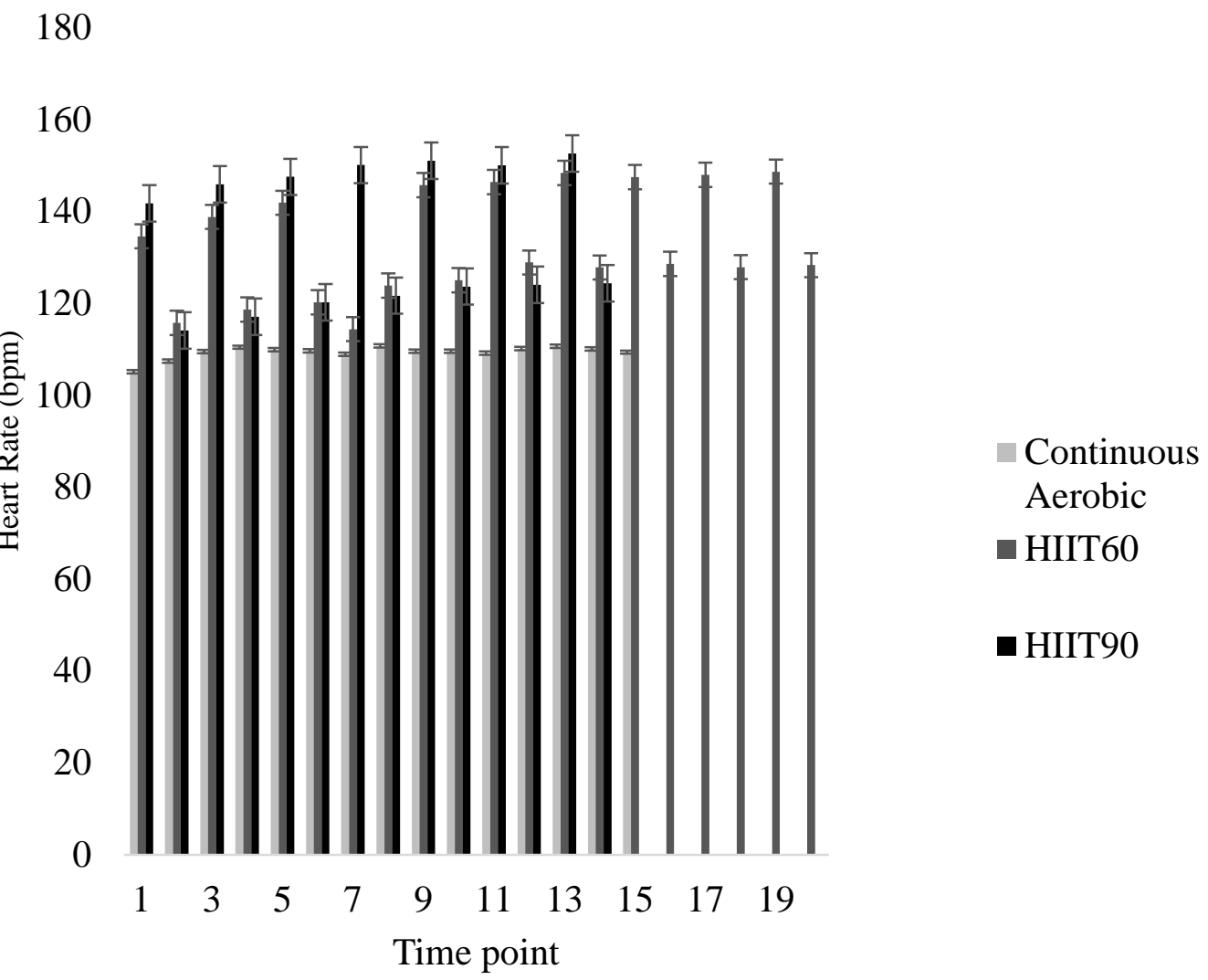

Figure 3.2 Average heart rate at each time point during continuous aerobic, HIIT60, and HIIT90.

Oxygen consumption measurements following the exercise conditions are presented in Table 3.3 in which there was a condition interaction. The average $\mathrm{VO}_{2}$ of HIIT60 and HIIT90 were not significantly different from one another at a 0.05 significance level. There were significant differences between oxygen consumptions when comparing the 0 minute post $\mathrm{VO}_{2}$ of HIIT60 and HIIT90 compared to the continuous aerobic exercise. There was no significant difference between the 0 minute post $\mathrm{VO}_{2}$ and the 30 minute post $\mathrm{VO}_{2}$ in the continuous aerobic exercise. There was a significant difference between the 0 minute post $\mathrm{VO}_{2}$ and 30 minute post $\mathrm{VO}_{2}$ in $\mathrm{HIIT60}$ 
at a 0.05 significance level. There was also a significant difference between the 0 minute post $\mathrm{VO}_{2}$ and the 30 minutes post $\mathrm{VO}_{2}$ in $\mathrm{HITT} 90$ at a 0.05 significance level.

Table 3.3 Post oxygen consumption immediately and 30 minutes following the exercise conditions

\begin{tabular}{lll}
\hline & 0 Min & 30 Min Post \\
& $\begin{array}{l}\text { Post } \\
(\mathrm{M} \pm \mathrm{SD}) \\
(\mathrm{M} \pm \mathrm{SD})\end{array}$ & $\mathrm{N}=14$ \\
& $\mathrm{~N}=14$ \\
\hline Continuous Post Oxygen Consumption $(\mathrm{mL} / \mathrm{kg} / \mathrm{min})$ & 4.2264 & 4.3564 \\
HIIT60 Post Oxygen Consumption $(\mathrm{mL} / \mathrm{kg} / \mathrm{min})$ & $5.0914^{\mathrm{ab}}$ & 4.6371 \\
HIIT90 Post Oxygen Consumption $(\mathrm{mL} / \mathrm{kg} / \mathrm{min})$ & $4.9864^{\mathrm{ab}}$ & 4.6807 \\
\hline
\end{tabular}

a $p<0.05$ compared to continuous aerobic 0 min post

b $p<0.05$ compared to 30 min post

\section{Exercise Perceptions during the Exercise}

Average RPE between conditions are presented in Table 3.4 and Figure 3.3 in which there was a condition interaction as well as a significant time interaction. The average RPE for the continuous aerobic exercise was 9.7 during the even time points of the continuous aerobic exercise while it was 12.1 for the high intensity intervals of the HIIT60 condition, and 12.5 for the high intensity intervals of the HIIT90 condition. There was an average RPE of 9.8 for the continuous aerobic condition during the odd time points while there was a 10.4 for the low intensity HIIT60 conditions and a 10.3 for the low intensity of the HIIT90 conditions. The RPE of HIIT60 and HIIT90 was higher at both the high and low intensities compared to continuous aerobic exercise. The RPE of the high intensity in both HIIT60 and HIIT90 was also higher than the low intensity of the given conditions. 
Table 3.4 Average ratings of perceived exertion during the exercise

\begin{tabular}{lll}
\hline Variable & $\begin{array}{l}\text { High Interval RPE } \\
(\mathrm{M} \pm \mathrm{SD}) \\
\mathrm{N}=14\end{array}$ & $\begin{array}{l}\text { Low Interval RPE } \\
(\mathrm{M} \pm \mathrm{SD}) \\
\mathrm{N}=14\end{array}$ \\
\hline Continuous Average RPE $^{*}$ & $9.7 \pm 0.4$ & $9.8 \pm 0.3$ \\
HIIT60 Average RPE & $12.1 \pm 0.9^{\mathrm{ac}}$ & $10.4 \pm 0.6^{\mathrm{a}}$ \\
HIIT90 Average RPE & $12.5 \pm 0.6^{\mathrm{abc}}$ & $10.3 \pm 0.3^{\mathrm{a}}$ \\
\hline
\end{tabular}

* High interval $\mathrm{HR}=$ odd time point HR; low interval $\mathrm{HR}=$ even time point $\mathrm{HR}$

a $p<0.008$ compared to continuous

b $p<0.008$ compared to HIIT60

c $p<0.008$ compared to low interval RPE

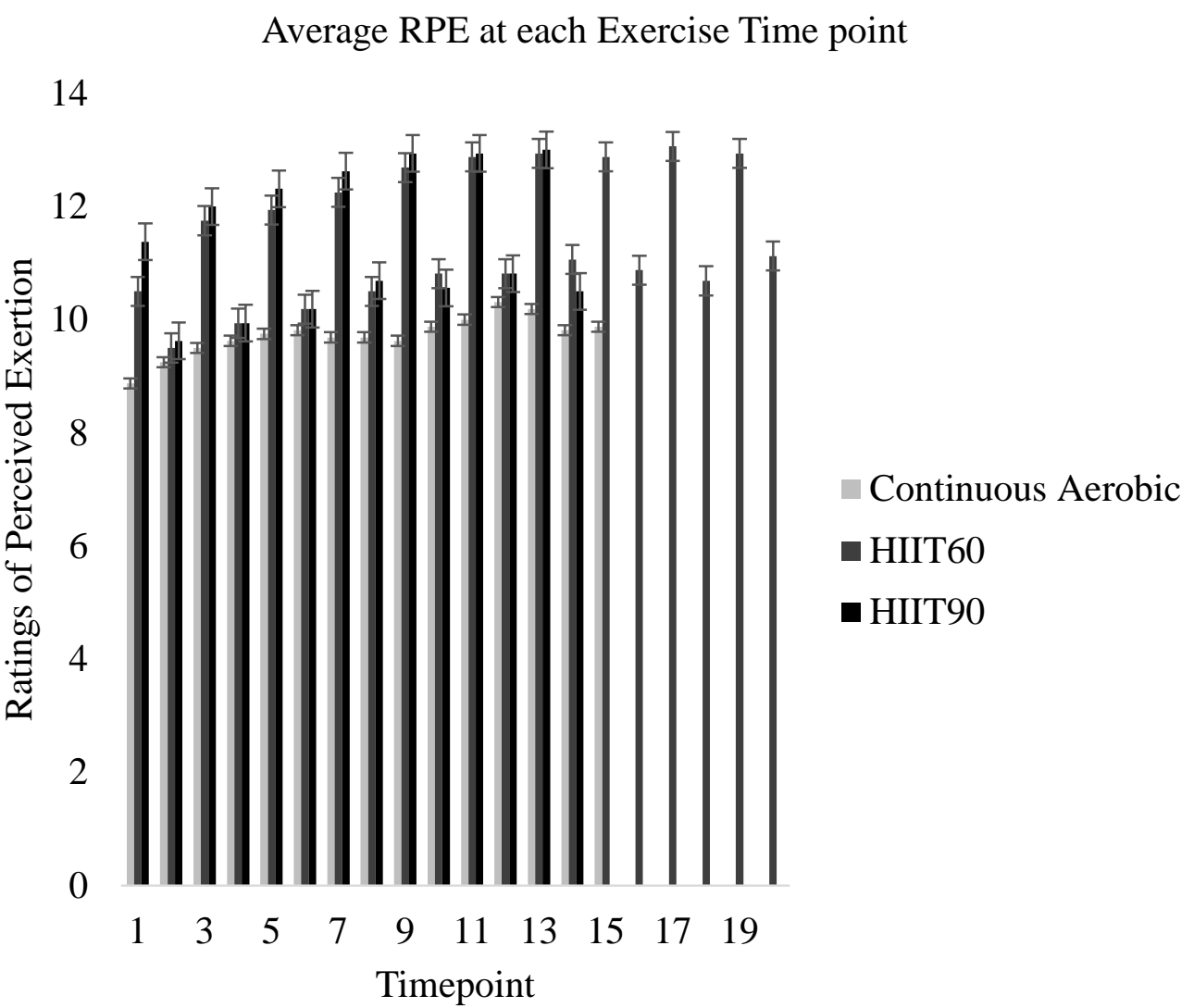

Figure 3.3 Average RPE at each time point during continuous aerobic, HIIT60, and HIIT90. 
Exercise enjoyment during the exercise are presented in Table 3.5 and figure 3.4. Average EES was not significantly different between conditions $(p<0.05)$. The average EES during the continuous aerobic was 4.5331 while HIIT60 was 4.3714, HIIT90 was 4.5007.

Table 3.5 Average EES between conditions

\begin{tabular}{lllll}
\hline Variables & $\begin{array}{l}\text { Mean } \\
\mathrm{N}=14\end{array}$ & SD & $\begin{array}{l}\text { Mean } \\
\text { Rank }\end{array}$ & $\begin{array}{l}\text { Condition } \\
p \text {-value }\end{array}$ \\
\hline Continuous Average EES & 4.5 & 1.1 & 1.8 & 0.571 \\
HIIT60 Average EES & 4.4 & 0.6 & 2.1 & \\
HIIT90 Average HIIT90 & 4.5 & 0.6 & 2.1 & \\
\hline
\end{tabular}




\section{Average EES at each Time Point}

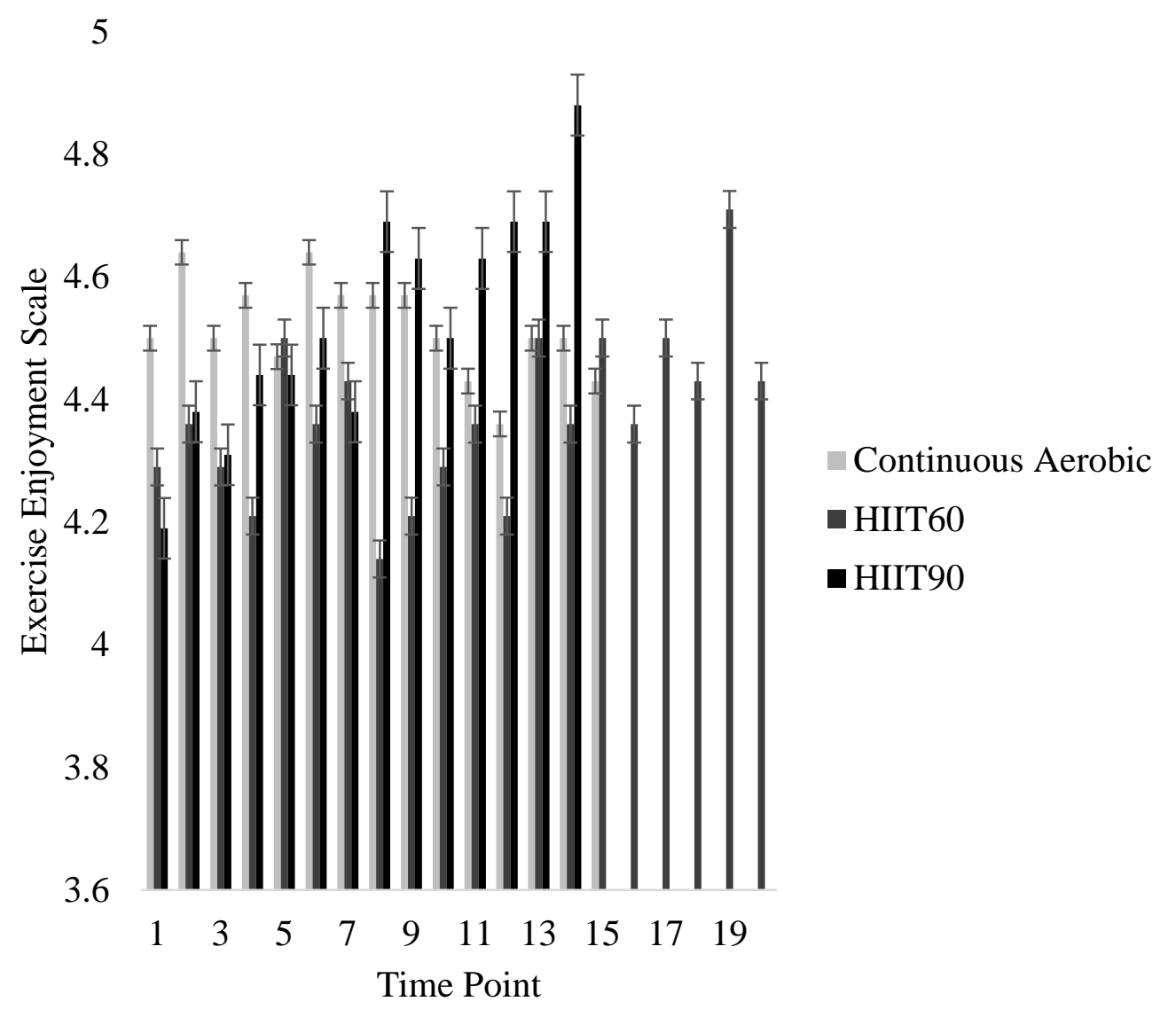

Figure 3.4 Average EES at each time point during continuous aerobic, HIIT60, and HIIT90.

\section{$\underline{\text { Post Exercise Perceptions }}$}

Post exercise FS are presented in Table 3.6, Table 3.7, and Table 3.8 in which there was a time interaction in the HIIT60 condition. There were no significant differences between conditions within the 5 minute or 35 minute post exercise FS. There was also no significant difference between the change of the 5 minute or 35 minute post exercise FS in the continuous aerobic and HIIT90 exercise conditions. The change in FS was only significantly different in the HIIT60 exercise condition. The FS increased from 
a 2.79 in the 5 minute post FS to a 3.71 in the 35 minute post FS. There was no significant difference in FS when comparing the 5 minute post FS of continuous aerobic to HIIT60 and HIIT90. However, HIIT90 was significantly higher than HIIT60 in the FS 5 minutes following the exercise $(\mathrm{p}<0.05)$. There was also no significant difference in FS when comparing the 35 minute post FS of the three exercise conditions.

Table 3.6 FS 5 minutes and 35 minutes following the exercise conditions

\begin{tabular}{|c|c|c|c|c|c|}
\hline Variables & \multicolumn{2}{|c|}{$\begin{array}{l}5 \text { Min Post FS } \\
(\mathrm{M} \pm \mathrm{SD}) \\
\mathrm{N}=14\end{array}$} & \multicolumn{3}{|c|}{$\begin{array}{l}35 \text { Min Post FS } \\
(\mathrm{M} \pm \mathrm{SD}) \\
\mathrm{N}=14\end{array}$} \\
\hline Continuous FS & \multicolumn{2}{|c|}{$3.4 \pm 0.9$} & \multicolumn{3}{|c|}{$3.4 \pm 1.2$} \\
\hline HIIT60 FS & \multicolumn{2}{|c|}{$2.8 \pm 1.6$} & \multicolumn{3}{|c|}{$3.7 \pm 1.1^{\mathrm{a}}$} \\
\hline HIIT90 FS & \multicolumn{2}{|c|}{$3.6 \pm 1.0^{\mathrm{b}}$} & \multicolumn{3}{|c|}{$3.9 \pm 0.8$} \\
\hline \multicolumn{6}{|c|}{$\begin{array}{l}\text { a } p<0.05 \text { compared } \\
\text { b } p<0.05 \text { compared to HIIT60 }\end{array}$} \\
\hline \multicolumn{6}{|c|}{ Table 3.75 minute post FS between conditions } \\
\hline Variables & & $\begin{array}{l}\text { Mean } \\
\mathrm{N}=14\end{array}$ & SD & $\begin{array}{l}\text { Mean } \\
\text { Rank }\end{array}$ & $\begin{array}{l}\text { Condition } \\
p \text {-value }\end{array}$ \\
\hline Continuous $5 \mathrm{~m}$ & Dst FS & 3.4 & 0.9 & 1.9 & 0.123 \\
\hline HIIT60 5 minut & & 2.8 & 1.6 & 1.8 & \\
\hline HIIT90 5 minut & & 3.6 & 1.0 & 2.3 & \\
\hline
\end{tabular}

Table 3.835 minute post FS between conditions

\begin{tabular}{lllll}
\hline Variables & $\begin{array}{l}\text { Mean } \\
\mathrm{N}=14\end{array}$ & SD & Mean Rank & $\begin{array}{l}\text { Condition } \\
p \text {-value }\end{array}$ \\
\hline Continuous 35 minute post FS & 3.4 & 1.1 & 1.8 & 0.248 \\
HIIT60 35 minute post FS & 2.7 & 1.1 & 2.1 & \\
HIIT90 35 minute post FS & 3.9 & 0.8 & 2.2 & \\
\hline
\end{tabular}


Post exercise PACES are presented in Table 3.9, Table 3.10, and Table 3.11 in which there was a condition interaction in the 5 minutes post exercise PACES. The change in PACES from 5 minutes post to 35 minutes post were not significantly different in any of the conditions. There was a significant difference in the 5 minute post PACES. HIIT 60 and HIIT90 were both significantly higher than continuous aerobic exercise. HIIT90 was also significantly higher than HIIT60. There was no significant differences in 35 minute post PACES. There was a significant difference in the average post exercise PACES conditions $(\mathrm{p}<0.05)$. The continuous exercise condition had an average PACES of 4.8479 and a mean rank of 1.64 while HIIT60 had an average PACES of 5.2114 and a mean rank of 1.86 and HIIT90 with an average PACES of 5.6279 and a mean rank of $2.5(\mathrm{p}<0.05)$.

Table 3.9 PACES 5 minutes and 35 minutes following the exercise conditions

\begin{tabular}{lll}
\hline \multirow{2}{*}{ Variables } & $\begin{array}{l}5 \text { Min Post PACES } \\
(\mathrm{M} \pm \mathrm{SD})\end{array}$ & $\begin{array}{l}\text { 35 Min Post PACES } \\
(\mathrm{M} \pm \mathrm{SD})\end{array}$ \\
& $\mathrm{N}=14$ & $\mathrm{~N}=14$ \\
\hline Continuous PACES & $4.8 \pm 0.8$ & $4.9 \pm 1.0$ \\
HIIT60 PACES & $5.2 \pm 0.7$ & $5.2 \pm 0.7$ \\
HIIT90 PACES & $5.7 \pm 0.6$ & $5.6 \pm 0.6$ \\
\hline
\end{tabular}

Table 3.105 minute post PACES between conditions

\begin{tabular}{lllll}
\hline Variables & $\begin{array}{l}\text { Mean } \\
\text { N=14 }\end{array}$ & SD & Mean Rank & $\begin{array}{l}\text { Condition } \\
p \text {-value }\end{array}$ \\
\hline Continuous 5 min post PACES & 4.8 & 0.8 & 1.5 & 0.006 \\
HIIT60 5 min post PACES & 5.2 & 0.7 & 1.9 & \\
HIIT90 5 min post PACES & 5.7 & 0.6 & 2.6 & \\
\hline
\end{tabular}


Table 3.1135 minute post PACES between conditions

\begin{tabular}{lllll}
\hline Variables & $\begin{array}{l}\text { Mean } \\
\text { N=14 }\end{array}$ & SD & Mean Rank & $\begin{array}{l}\text { Condition } \\
p \text {-value }\end{array}$ \\
\hline Continuous 5 min post PACES & 4.9 & 1.0 & 1.7 & 0.185 \\
HIIT60 Average PACES & 5.2 & 0.7 & 2.0 & \\
HIIT90 Average PACES & 5.6 & 0.6 & 2.4 & \\
\hline
\end{tabular}

Participant exercise preferred order is presented in Table 3.12 in which there was a condition interaction. There was a significant preference order of the three exercise conditions in that HIIT90 was the most preferred, followed by HIIT60, and continuous aerobic training being the least preferred exercise condition $(\mathrm{p}<0.05)$. HIIT90 was the most preferred condition by all but three participant while HIIT60 was the least preferred condition by only two participant as well. HIIT90 had a mean ranking of 1.29 , followed by HIIT60 with a mean ranking of 1.93, and finally continuous aerobic training with a mean ranking of $2.79(\mathrm{p}<0.05)$.

Table 3.12 Preference order of the conditions

\begin{tabular}{lllll}
\hline Variables & $\begin{array}{l}\text { Mean } \\
\mathrm{N}=14\end{array}$ & SD & Mean Rank & $\begin{array}{l}\text { Condition } \\
p \text {-value }\end{array}$ \\
\hline Continuous Aerobic & 2.8 & 0.6 & 2.8 & 0.001 \\
HIIT60 & 1.9 & 0.6 & 1.9 & \\
HIIT90 & 1.3 & 0.5 & 1.3 & \\
\hline
\end{tabular}

\section{$\underline{\text { Discussion }}$}

The aim of this study was to analyze, through a mixed methods approach, whether participants prefer HIIT in comparison to continuous aerobic exercise. More specifically, the study observed feelings of enjoyment, ratings of perceived exertion, as well as 
exercise preferences both during and following exercise. The participants preferred HIIT over continuous aerobic exercise. This was made evident by the rankings of exercise preferences as well as enjoyment responses following the exercise sessions.

The participants within this study can be generalized as overweight or moderately obese older individuals who are currently sedentary. The participants in this study were included if they were between the age of 30 to 55 with a BMI of 25 to $35 \mathrm{~kg} / \mathrm{m}^{2}$. This differs from past HIIT perceptual investigations that utilized younger individuals (18-33 years old). ${ }^{25-28}$ The HIIT investigations that utilized a treadmill as the mode of exercise also utilized recreationally active individuals. ${ }^{27}$ The current study utilized participants who were overweight or moderately obese older individuals as a way of delimiting to participants that were currently at risk for metabolic conditions such as CVD, diabetes mellitus, and metabolic syndrome.

The HIIT exercises were more preferred over the continuous aerobic exercise. This was made evident when the participants were asked to order the exercise conditions from most preferred (1) to least preferred (3). The most preferred condition was HIIT90, which was preferred by all but three participants. Of those three participants, HIIT60 was the most preferred by two of the participants while the continuous aerobic exercise was the most preferred by one participant. HIIT60 was the second most preferred followed by the continuous aerobic condition which was least preferred by all but two participants. It was hypothesized that HIIT would be more preferred than the continuous aerobic exercise, we therefore accept the hypothesis based on the participant's preferred exercise conditions. 
Exercise intensity was higher in the HIIT60 and HIIT90 conditions in comparison to the continuous aerobic condition. The exercise intensity was higher during both the high intensity repetitions and the low intensity repetitions in terms of average heart rate at each repetition. The overall RPE was also higher during HIIT60 and HIIT90 compared to the continuous aerobic exercise. A higher exercise intensity during the HIIT conditions can also be demonstrated when observing that the oxygen consumption of both HIIT60 and HIIT90 was significantly higher than the continuous aerobic condition immediately following the exercises. Higher RPE and HR values during the HIIT conditions did not appear to have an effect on the perceptions and preferences of the exercise conditions. Participants anecdotally stated that the HIIT conditions were more preferred because of a greater challenge as well as less monotony during the exercises.

The enjoyment of the exercises, as measured using EES, was not significantly different during conditions. This is unlike past findings that demonstrate higher exercise enjoyment in exercise conditions similar to that utilized in this investigation. ${ }^{25,28}$ A lack of different enjoyment during the HIIT conditions demonstrates that affect during the exercise was low despite higher preferences for the HIIT exercises. Ekkekakis and colleagues theorized that exercise affect would be low when exercising at intensities above ventilatory threshold, the affective affect would then be expected to rise following the exercise session in a manner of Solomon's Opponent Process Theory. ${ }^{65}$ Solomon’s Opponent Process theory states that affect will be low immediately following the exercise and will then rise, back to baseline affect or higher than baseline affect, as the time extends past the exercise session. ${ }^{56}$ These findings support both theories when analyzing 
EES during the exercise and FS and PACES after the exercise. It can be assumed, based on Ekkekakis’s theory, that exercise enjoyment during the HIIT exercise sessions was low because the intensities during HIIT were presumably above ventilatory threshold at $80-85 \%$ of the participant's estimated maximum heart rate. ${ }^{65}$ Ventilatory threshold has been shown to be achieved between $60-80 \%$ of an untrained individual's maximum heart rate. ${ }^{66-68}$

The exercise preferences can be expanded upon when analyzing the enjoyment during exercise as well as the perceptions following the exercise conditions. Participants rated physical activity enjoyment, based on the PACES, as higher in both HIIT60 as well as HIIT90. Positive post exercise perceptions were higher in the HIIT conditions, 5 minutes following the exercise sessions when measuring general feelings in the HIIT60 condition as well as both HIIT conditions when measuring physical activity enjoyment. Participants indicated feeling greater than "good” five minutes following the HIIT60 session with the FS. The feelings of physical activity enjoyment, 5 minutes following the exercise sessions were highest in the HIIT60 and HIIT90 conditions. The PACES scale is a 7 point scale in which 4 would be the neutral value of a given feeling. ${ }^{47}$ The HIIT60 and HIIT90 experienced the greatest feelings of enjoyment based on the PACES. Only the HIIT60 exercise condition experienced a significant rise in general feelings, on the FS. The hypothesis that affective valence would increase following the commencement of exercise, can therefore be accepted with HIIT60 when analyzing the FS. Physical activity enjoyment 35 minutes following the exercise session did not increase or 
decrease. Therefore, the hypothesis regarding post exercise affective valence cannot be accepted when observing HIIT60 or HIIT90 in terms of the PACES.

The current study did not observe low perceptions of affect during the exercise. Previous findings have found that in task affect of the exercise session were lower during the exercise of the HIIT conditions lasting longer than 60 seconds. ${ }^{25,28}$ This difference in affect could be the result of lower intensities during the high intensity repetitions. Past findings have also shown a greater magnitude of change in post exercise affect. ${ }^{25,28}$ This could be due to the difference in intensities of the high intensity repetition as well. The current study utilized lower intensities, of $80 \%$ estimated maximum heart rate during the high intensity repetitions, for a number of reasons. The current study utilized a treadmill while past studies have mainly utilized a cycle ergometer. ${ }^{25,28,69}$ The utilization of a treadmill, as well as the inclusion of an older population (30-55 years old), that were classified as sedentary, resulted in safety concerns that needed to be addressed with lower intensities for an acute exercise study. A difference in the magnitude of post exercise affect can also be a result of the post exercise oxygen consumption measurements. The major draw to HIIT as an exercise form is the reduced amount of time spent exercising. ${ }^{25,28,30,35}$ The current study did not match the conditions for energy expenditure, during the exercise, as a way of keeping the difference in exercise time significant. For those reasons, post exercise oxygen consumption was measured as a way of determining whether post exercise metabolic requirements would be higher in the HIIT conditions. The utilization of post exercise oxygen consumption therefore possibly 
clouded the perceptions of the exercise as the questionnaires were given immediately following the 5 minute oxygen consumption.

The focus of the current study was the exercise preference and perceptions of HIIT, and there were several delimitations to the design. One delimitation was the research population was intended for men and women between the age of 30 to 55 years old who are overweight and moderately obese based on a BMI of 25-35 kg/m².

The current study also had several limitations to the study design. One limitation was the participant's lack of familiarity with HIIT which could have caused some unwanted stress and anxiety while exercising at uncomfortable and challenging intensities. A second limitation was the participant's lack of familiarity with exercise studies which also could have caused unwanted stress and anxiety during both the exercise and following the exercise such as the measurements of post exercise oxygen consumption. Attempts were made to account for any unwanted stress and anxiety caused by the first and second limitations. A third limitation was the use of only one exercise enjoyment indicator during the exercise sessions. This was due to the lack of time to measure exercise enjoyment during each repetition as well as the lack of reasonable options to measure exercise enjoyment. A forth limitation was that the participants did not exercise at the ideal exercise intensities for the entire exercise repetition considering it took some time for the heart rate to reach the ideal intensity. Ventilatory threshold was not measured as well. This was due to the need to decrease the amount of stress and anxiety during the exercise that could have clouded the perceptions and preferences of the exercise conditions. The chosen exercise intensity of the high intensity was chosen as 
a way of keeping the intensity high as well as being above the ventilatory threshold of the average population.

In summary, HIIT is a more preferred exercise over continuous aerobic exercise. Preferences for HIIT are shown in post exercise physical activity enjoyment as well as a stated preference order. The physiological demands during HIIT are higher over continuous aerobic exercise as seen in RPE during HIIT and cardiovascular demands during and immediately following HIIT. The higher intensities do not appear to affect the preferences of HIIT over continuous aerobic. However, HIIT may be poorly tolerated as the only mode of exercise due to the increased intensity and prolonged muscle soreness that would be anticipated from HIIT performed multiple days in a row. 


\section{CHAPTER FOUR}

\section{DISCUSSIONS AND CONCLUSIONS}

High intensity interval training consists of a shorter bout of exercise which would

possibly result in improved exercise adherence. The purpose of this study was to analyze, through a mixed methods approach, whether participants prefer HIIT in comparison to continuous aerobic exercise. The primary hypothesis was that participants would prefer the HIIT conditions more than the continuous aerobic condition. This hypothesis was confirmed as participants significantly ranked exercise conditions in the order of HIIT90, HIIT60, followed by the continuous aerobic exercise. This can be expanded upon when analyzing the enjoyment of the physical activity after the exercise as well. The five minute post exercise PACES was significantly higher in the HIIT60 and HIIT90 conditions showing that the participants enjoyed the HIIT conditions immediately following the exercise conditions.

The secondary hypothesis was that exercise affect would be low while exercising at higher intensities and would then increase following the exercise session. This hypothesis could not be completely confirmed. Exercise enjoyment during the exercise session, as measured by the EES, was not different in the HIIT conditions. The HIIT condition intensity, as measured by RPE and HR during the exercise as well as oxygen consumption following the exercise session, was higher in comparison to the continuous aerobic condition. This section of the hypothesis can be confirmed when analyzing the enjoyment during the exercise session. However, post exercise perceptions did not clearly 
rise following the exercise as was expected. General feelings, as measured by the FS five minutes following the exercise condition, were not different between conditions. There was also no difference between conditions in general feelings 35 minutes following the exercise conditions. Physical activity enjoyment was ranked higher in the HIIT90 and HIIT60 conditions, using PACES, 5 minutes following the exercise conditions. This trend did not continue when analyzing physical activity enjoyment 35 minutes following the exercise conditions. There was also no difference in increase or decrease of physical activity enjoyment from the 5 minute to 35 minute post exercise questionnaires as expected.

The third hypothesis was that post exercise enjoyment would be higher in the HIIT conditions compared to the continuous aerobic condition. This hypothesis cannot be completely accepted as perceptions of enjoyment were not higher at each post exercise time point. Physical activity enjoyment was higher in the HIIT60 and HIIT90 exercise conditions five minutes following the exercise. This trend did not continue 35 minutes following the exercise conditions however.

The current study demonstrates that HIIT is a preferred exercise to take part in on an acute basis. Anecdotal responses demonstrate that this was due to a decrease in monotony during the exercise as well as the feeling that the work demands were higher which therefore leads to increasing the amount of work completed over a shorter period of time. These findings result in the need to expand further on the perceptions and preferences of HIIT. A more in depth understanding of HIIT will require the need to increase the intensity of the HIIT conditions. The HIIT conditions within this study were 
not matched for energy expenditure during the exercise session. This was due to risk concerns as well as the lack of familiarity of HIIT within the population that can be generalized as overweight to moderately obese adults who are currently sedentary. The current study also utilized a single exercise session for each of the three conditions. A longitudinal study of the perceptions and preferences of HIIT would result in the ability to increase the intensity, to a near maximal age predicted heart rate, as well as increase the amount of time spent in each repetition. Increasing the intensity and time spent exercising at higher intensities would then allow for the physiological responses of HIIT to increase. 
REFERENCES CITED 
1. Blair S, Cheng Y, Scott Holder J. Is physical activity or physical fitness more important in defining health benefits? Med Sci Sports Exerc. 200106;33(6):S379S399.

2. Blair S, Horton E, Leon A, et al. Physical activity, nutrition, and chronic disease. Med Sci Sports Exerc. 199603;28(3):335-349.

3. Buttar HS, Li T, Ravi N. Prevention of cardiovascular diseases: Role of exercise, dietary interventions, obesity and smoking cessation. Exp Clin Cardiol. 2005;10(4):229-249.

4. National diabetes statistics report, 2014. center of disease control. http://www.cdc.gov/diabetes/pubs/statsreport14/national-diabetes-report-web.pdf. Published 2014.

5. Huang ES, Basu A, O’Grady M, Capretta JC. Projecting the Future Diabetes Population Size and Related Costs for the U.S. Diabetes Care. 2009;32(12):22252229. doi:10.2337/dc09-0459.

6. Heart Disease. Center of disease control. http://www.cdc.gov/nchs/fastats/heartdisease.htm. Published April 8, 2015. Accessed April 30, 2015.

7. Heidenreich PA, Trogdon JG, Khavjou OA, et al. Forecasting the Future of Cardiovascular Disease in the United States A Policy Statement From the American Heart Association. Circulation. 2011;123(8):933-944. doi:10.1161/CIR.0b013e31820a55f5.

8. Haskell W, Lee I-M, Pate R, et al. Physical activity and public health updated recommendations for adults from the american college of sports medicine and the american heart association. Circulation. 2007;116:1081-1093.

9. $\quad$ FastStats. http://www.cdc.gov/nchs/fastats/exercise.htm. Accessed April 12, 2016.

10. Owen N, Sparling PB, Healy GN, Dunstan DW, Matthews CE. Sedentary behavior: emerging evidence for a new health risk. Mayo Clin Proc. 2010;85(12):1138-1141. doi:10.4065/mcp.2010.0444.

11. Schutzer KA, Graves BS. Barriers and motivations to exercise in older adults. Prev Med. 2004;39(5):1056-1061. doi:10.1016/j.ypmed.2004.04.003.

12. Mcauley E, Courneya KS, Rudolph DL, Lox CL. Enhancing Exercise Adherence in Middle-Aged Males and Females. Prev Med. 1994;23(4):498-506.

doi:10.1006/pmed.1994.1068. 
13. Heesch KC, Maase LC. Lack of Time for Physical Activity: Perception or Reality for African American and Hispanic Women? Women Health. 2004;39(3):45-62. doi:10.1300/J013v39n03_04.

14. Osuji T, Lovegreen S, Elliot M, Brownson RC. Barriers to Physical Activity Among Women in the Rural Midwest. Women Health. 2006;44(1):41-55. doi:10.1300/J013v44n01_03.

15. Caperchione CM, Vandelanotte C, Kolt GS, et al. What a Man Wants: Understanding the Challenges and Motivations to Physical Activity Participation and Healthy Eating in Middle-Aged Australian Men. Am J Mens Health. 2012;6(6):453-461. doi:10.1177/1557988312444718.

16. Little JP, Safdar A, Wilkin GP, Tarnopolsky MA, Gibala MJ. A practical model of low-volume high-intensity interval training induces mitochondrial biogenesis in human skeletal muscle: potential mechanisms. J Physiol. 2010;588(6):1011-1022. doi:10.1113/jphysiol.2009.181743.

17. You T, Berman DM, Ryan AS, Nicklas BJ. Effects of Hypocaloric Diet and Exercise Training on Inflammation and Adipocyte Lipolysis in Obese Postmenopausal Women. J Clin Endocrinol Metab. 2004;89(4):1739-1746. doi:10.1210/jc.2003-031310.

18. Boutcher SH. High-intensity intermittent exercise and fat loss. J Obes. 2011;2011:868305. doi:10.1155/2011/868305.

19. Racil G, Ounis OB, Hammouda O, et al. Effects of high vs. moderate exercise intensity during interval training on lipids and adiponectin levels in obese young females. Eur J Appl Physiol. 2013;113(10):2531-2540. doi:10.1007/s00421-0132689-5.

20. Little JP, Francois ME. High-Intensity Interval Training for Improving Postprandial Hyperglycemia. Res Q Exerc Sport. 2014;85(4):451-456. doi:10.1080/02701367.2014.963474.

21. Currie KD, Dubberley JB, McKELVIE RS, MacDONALD MJ. Low-Volume, High-Intensity Interval Training in Patients with CAD: Med Sci Sports Exerc. 2013;45(8):1436-1442. doi:10.1249/MSS.0b013e31828bbbd4.

22. Whyte LJ, Ferguson C, Wilson J, Scott RA, Gill JMR. Effects of single bout of very high-intensity exercise on metabolic health biomarkers in overweight/obese sedentary men. Metabolism. 2013;62(2):212-219.

doi:10.1016/j.metabol.2012.07.019. 
23. Gibala MJ, Gillen JB, Percival ME. Physiological and Health-Related Adaptations to Low-Volume Interval Training: Influences of Nutrition and Sex. Sports Med. 2014;44(2):127-137. doi:10.1007/s40279-014-0259-6.

24. Saanijoki T, Nummenmaa L, Eskelinen J-J, et al. Affective Responses to Repeated Sessions of High-Intensity Interval Training. Med Sci Sports Exerc. 2015. http://becs.aalto.fi/ Inummen/PDFs/Saanijoki_et_al_MSSE_2015.pdf. Accessed August 13, 2015.

25. Martinez N. Perceptual responses to high-intensity interval training in overweight and sedentary individuals. Sch Commons. January 2013:1-71.

26. Heinrich KM, Patel PM, O’Neal JL, Heinrich BS. High-intensity compared to moderate-intensity training for exercise initiation, enjoyment, adherence, and intentions: an intervention study. BMC Public Health. 2014;14(1):789. doi:10.1186/1471-2458-14-789.

27. Bartlett JD, Close GL, MacLaren DPM, Gregson W, Drust B, Morton JP. Highintensity interval running is perceived to be more enjoyable than moderate-intensity continuous exercise: Implications for exercise adherence. J Sports Sci. 2011;29(6):547-553. doi:10.1080/02640414.2010.545427.

28. Greeley S. The Impact of Continuous and Discontinuous Cycle Exercise on Affect: An Examination of the Dual-Mode Model. 2012. http://search.proquest.com/docview/1014403726/abstract/85EFD26B502E4B17PQ/ 1? accountid=28148. Accessed July 29, 2015.

29. Wisløff U, Støylen A, Loennechen JP, et al. Superior Cardiovascular Effect of Aerobic Interval Training Versus Moderate Continuous Training in Heart Failure Patients A Randomized Study. Circulation. 2007;115(24):3086-3094. doi:10.1161/circulationAHA.106.675041.

30. Gillen JB, Little JP, Punthakee Z, Tarnopolsky MA, Riddell MC, Gibala MJ. Acute high-intensity interval exercise reduces the postprandial glucose response and prevalence of hyperglycaemia in patients with type 2 diabetes. Diabetes Obes Metab. 2012;14(6):575-577. doi:10.1111/j.1463-1326.2012.01564.x.

31. Garber CE, Blissmer B, Deschenes MR, et al. Quantity and Quality of Exercise for Developing and Maintaining Cardiorespiratory, Musculoskeletal, and Neuromotor Fitness in Apparently Healthy Adults: Guidance for Prescribing Exercise. Med Sci Sports Exerc. 2011;43(7):1334-1359. doi:10.1249/MSS.0b013e318213fefb.

32. Carstairs GM. The Second Adolphe Abrahams Memorial Lecture Psychology of Athletic Performance. Br J Sports Med. 1970;5(2):73-81. doi:10.1136/bjsm.5.2.73. 
33. Krüger A. Training Theory and Why Roger Bannister was the First Four-Minute Miler. Sport Hist. 2006;26(2):305-324. doi:10.1080/17460260600786955.

34. Coyle EF. Very intense exercise-training is extremely potent and time efficient: a reminder. J Appl Physiol. 2005;98(6):1983-1984.

doi:10.1152/japplphysiol.00215.2005.

35. Little JP, Gillen JB, Percival ME, et al. Low-volume high-intensity interval training reduces hyperglycemia and increases muscle mitochondrial capacity in patients with type 2 diabetes. J Appl Physiol. 2011;111(6):1554-1560.

doi:10.1152/japplphysiol.00921.2011.

36. Whyte LJ, Gill JMR, Cathcart AJ. Effect of 2 weeks of sprint interval training on health-related outcomes in sedentary overweight/obese men. Metabolism. 2010;59(10):1421-1428. doi:10.1016/j.metabol.2010.01.002.

37. DeFronzo RA. Pathogenesis of type 2 diabetes mellitus. Med Clin North Am. 2004;88(4):787-835. doi:10.1016/j.mcna.2004.04.013.

38. Edgett BA, Foster WS, Hankinson PB, et al. Dissociation of Increases in PGC-1 $\alpha$ and Its Regulators from Exercise Intensity and Muscle Activation Following Acute Exercise. PLoS ONE. 2013;8(8):e71623. doi:10.1371/journal.pone.0071623.

39. Shiose K, Tobina T, Higaki Y, Kiyonaga A, Tanaka H. Effectiveness of submaximal intermittent exercise on muscle glycogen depletion, PGC-1 $\alpha$ and PDK-4 gene expression. Open J Mol Integr Physiol. 2012;02(04):119-126. doi:10.4236/ojmip.2012.24017.

40. Hood MS, Little JP, Tarnopolsky MA, Myslik F, Gibala MJ. Low-Volume Interval Training Improves Muscle Oxidative Capacity in Sedentary Adults: Med Sci Sports Exerc. 2011;43(10):1849-1856. doi:10.1249/MSS.0b013e3182199834.

41. Tjønna AE, Lee SJ, Rognmo Ø, et al. Aerobic Interval Training Versus Continuous Moderate Exercise as a Treatment for the Metabolic Syndrome A Pilot Study. Circulation. 2008;118(4):346-354. doi:10.1161/CIRCULATIONAHA.108.772822.

42. Tremblay A, Simoneau J-A, Bouchard C. Impact of exercise intensity on body fatness and skeletal muscle metabolism. Metabolism. 1994;43(7):814-818. doi:10.1016/0026-0495(94)90259-3.

43. Trapp EG, Chisholm DJ, Freund J, Boutcher SH. The effects of high-intensity intermittent exercise training on fat loss and fasting insulin levels of young women. Int J Obes. 2008;32(4):684-691. doi:10.1038/sj.ijo.0803781.

44. Boudou P, Sobngwi E, Mauvais-Jarvis F, Vexiau P, Gautier JF. Absence of exercise-induced variations in adiponectin levels despite decreased abdominal 
adiposity and improved insulin sensitivity in type 2 diabetic men. Eur J Endocrinol. 2003;149(5):421-424. doi:10.1530/eje.0.1490421.

45. Mourier A, Gautier J-F, Kerviler ED, et al. Mobilization of Visceral Adipose Tissue Related to the Improvement in Insulin Sensitivity in Response to Physical Training in NIDDM: Effects of branched-chain amino acid supplements. Diabetes Care. 1997;20(3):385-391. doi:10.2337/diacare.20.3.385.

46. Guiraud DT, Nigam A, Gremeaux V, Meyer P, Juneau M, Bosquet L. HighIntensity Interval Training in Cardiac Rehabilitation. Sports Med. 2012;42(7):587605. doi:10.2165/11631910-000000000-00000.

47. Kendzierski D. Physical Activity Enjoyment Scale: Two Validation Studies. Human Kinetics Journals. http://journals.humankinetics.com/jsep-backissues/jsepvolume13issue1march/physicalactivityenjoymentscaletwovalidationstudi es. Published April 21, 2010. Accessed October 29, 2015.

48. Motl RW, Dishman RK, Saunders R, Dowda M, Felton G, Pate RR. Measuring enjoyment of physical activity in adolescent girls. Am J Prev Med. 2001;21(2):110117. doi:10.1016/S0749-3797(01)00326-9.

49. Salmon J, Owen N, Crawford D, Bauman A, Sallis JF. Physical activity and sedentary behavior: A population-based study of barriers, enjoyment, and preference. Health Psychol. 2003;22(2):178-188. doi:10.1037/0278-6133.22.2.178.

50. Rose EA, Parfitt G. Can the Feeling Scale Be Used to Regulate Exercise Intensity?: Med Sci Sports Exerc. 2008;40(10):1852-1860.

doi:10.1249/MSS.0b013e31817a8aea.

51. Hardy CJ. Not What, But How One Feels: The Measurement of Affect During Exercise. Human Kinetics Journals. http://journals.humankinetics.com/jsep-backissues/jsepvolume11issue3september/not-what-but-how-one-feels-themeasurement-of-affect-during-exercise. Published April 21, 2010. Accessed October 29, 2015.

52. Rejeski WJ, Best DL, Griffith P, Kenney E. Sex-Role Orientation and the Responses of Men to Exercise Stress. Res Q Exerc Sport. 1987;58(3):260-264. doi:10.1080/02701367.1987.10605459.

53. Williams DM, Dunsiger S, Ciccolo JT, Lewis BA, Albrecht AE, Marcus BH. Acute affective response to a moderate-intensity exercise stimulus predicts physical activity participation 6 and 12 months later. Psychol Sport Exerc. 2008;9(3):231245. doi:10.1016/j.psychsport.2007.04.002. 
54. Stanley DM, Cumming J. Are we having fun yet? Testing the effects of imagery use on the affective and enjoyment responses to acute moderate exercise. Psychol Sport Exerc. 2010;11(6):582-590. doi:10.1016/j.psychsport.2010.06.010.

55. Kilpatrick MW, Greeley SJ, Collins LH. The Impact of Continuous and Interval Cycle Exercise on Affect and Enjoyment. Res Q Exerc Sport. 2015;86(3):244-251. doi:10.1080/02701367.2015.1015673.

56. Solomon RL. The opponent-process theory of acquired motivation: The costs of pleasure and the benefits of pain. Am Psychol. 1980;35(8):691-712. doi:http://dx.doi.org.proxybz.lib.montana.edu/10.1037/0003-066X.35.8.691.

57. Ekkekakis P. Pleasure and displeasure from the body: Perspectives from exercise. Cogn Emot. 2003;17(2):213-239. doi:10.1080/02699930302292.

58. Gaskill SE, Walker AJ, Serfass RA, et al. Changes in Ventilatory Threshold with Exercise Training in a Sedentary Population: The Heritage Family Study. Int $J$ Sports Med. 2001;22(8):586-592. doi:10.1055/s-2001-18522.

59. Heidenreich PA, Trogdon JG, Khavjou OA, et al. Forecasting the Future of Cardiovascular Disease in the United States A Policy Statement From the American Heart Association. Circulation. 2011;123(8):933-944.

doi:10.1161/CIR.0b013e31820a55f5.

60. Schutzer KA, Graves BS. Barriers and motivations to exercise in older adults. Prev Med. 2004;39(5):1056-1061. doi:10.1016/j.ypmed.2004.04.003.

61. Heesch KC, Masse L. Lack of Time for Physical Activity: Perception or Reality for African American and Hispanic Women? Women Health. 2004;39(3):45-62. doi:10.1300/J013v39n03_04.

62. AHA/ACSM Health/Fitness Facility Pre-participation Screening Questionnaire. 1998.

63. Ferguson B. ACSM's Guidelines for Exercise Testing and Prescription 9th Ed. 2014. J Can Chiropr Assoc. 2014;58(3):328.

64. Tanaka H, Monahan KD, Seals DR. Age-predicted maximal heart rate revisited. $J$ Am Coll Cardiol. 2001;37(1):153-156. doi:10.1016/S0735-1097(00)01054-8.

65. Ekkekakis P, Hall EE, Petruzzello SJ. The Relationship Between Exercise Intensity and Affective Responses Demystified: To Crack the 40-Year-Old Nut, Replace the 40-Year-Old Nutcracker! Ann Behav Med. 2008;35(2):136-149. doi:10.1007/s12160-008-9025-z. 
66. Katch V, Weltman A, Sady S, Freedson P. Validity of the relative percent concept for equating training intensity. Eur J Appl Physiol. 1978;39(4):219-227. doi:10.1007/BF00421445.

67. Kennon F. The Use of the Ventilatory Anaerobic Threshold for the Development of Exercise Guidelines. Comput Biol Med. 1989;19(5):307-317.

68. Meyer T, Gabriel HH, Kindermann W. Is determination of exercise intensities as percentages of VO2max or HRmax adequate? Med Sci Sports Exerc. 1999;31(9):1342-1345.

69. Astorino TA, Allen RP, Roberson DW, Jurancich M, Lewis R, McCarthy K. Attenuated RPE and leg pain in response to short-term high-intensity interval training. Physiol Behav. 2012;105(2):402-407. doi:10.1016/j.physbeh.2011.08.040. 
APPENDICES 
APPENDIX A:

AHA/ACSM HEALTH/FITNESS FACILITY PREPARTICIPATION SCREENING QUESTIONNAIRE 


\section{AHA/ACSM Health/Fitness Facility Preparticipation Screening Questionnaire}

Assess your health status by marking all true statements

History

You have had:

a heart attack

heart surgery

cardiac catheterization

coronary angioplasty (PTCA)

pacemaker/implantable cardiac

defibrillator/hythm disturbance

heart valve disease

heart failure

heart transplantation

congenital heart disease

Symptoms

You experience chest discomfort with exertion.

You experience unreasonable breathlessness.

You experience dizziness, fainting, or blackouts.

You take heart medications.

\section{Other health issues}

You have diabetes.

You have asthma or other lung disease.

You have burning or cramping sensation in your lower

legs when walking short distances.

You have musculoskeletal problems that limit your

physical activity.

You have concerns about the safety of exercise.

You take prescription medication(s).

You are pregnant.

If you marked any of these statements in this section, consult your physician or other appropriate health care provider before engaging in exercise. You may need to use a facility with a medically qualified staff.

\section{Cardiovascular risk factors}

You are a man older than 45 years.

You are a woman older than 55 years,

have had a hysterectomy, or are postmenopausal.

You smoke, or quit smoking within the previous 6 months.

Your blood pressure is $>140 / 90 \mathrm{~mm} \mathrm{Hg}$.

You do not know your blood pressure.

You take blood pressure medication.

Your blood cholesterol level is $>200 \mathrm{mg} / \mathrm{dL}$.

You do not know your cholesterol level.

You have a close blood relative who had a heart attack or heart surgery before age 55 (father or brother) or age 65 (mother or sister).

You are physically inactive (i.e., you get $<30$ minutes of physical activity on at least 3 days per week).

You are $>20$ pounds overweight.
If you marked two or more of the statements in this section you should consult your physician or other appropriate health care provider before engaging in exercise. You might benefit from using a facility with a professionally qualified exercise staff to guide your exercise program. 
APPENDIX B:

SUBJECT CONSENT FORM FOR PARTICIPATION IN HUMAN RESEARCH AT MONTANA STATE UNIVERSITY 


\section{SUBJECT CONSENT FORM FOR PARTICIPATION IN HUMAN RESEARCH AT MONTANA STATE UNIVERSITY}

Study Title: The perceptual responses to high intensity interval training among overweight and obese individuals (Pilot Study)

Investigators: John Halvorson, Mary Miles Ph.D

Dept. of Health and Human Development

Herrick Hall, Montana State University

Bozeman, MT 59717-3540

Phone: (406) 994-5001

John.halvorson1@msu.montana.edu ; mmiles@montana.edu

Summary:

You are being asked to volunteer in a research study of how people feel during high intensity interval training (HIIT) in comparison to treadmill walking at the same speed and intensity for a longer amount of time. HITT is an exercise program in which you complete between 1-4 minutes at a very high intensity followed by 1-4 minutes at a very low intensity. The high/low intensity is then completed anywhere between 5 to 10 times. As a participant, you will be asked to participate in 2 different HIIT sessions as well as one treadmill walking session. We will ask you questions both during and after each exercise session about how you felt during the exercise and how much you enjoyed the exercise

You are being asked to take part in 5-8 sessions in the laboratory. Each session will range between 1-2 hours in length.

Purpose:

The purpose of this study is to better understand if participants enjoy HIIT more that continuous treadmill walking. This will help us to understand if HIIT is an exercise program that individuals would do in order to exercise on a more regular basis. Your responses to the exercise sessions will help us to better understand our research questions.

Participants in the study: You are being asked to participate in this study because you fit the criteria to participate. The criteria will be confirmed in the baseline visit. You may not be a participant if you do not meet the eligibility requirements of our baseline screening based on health history and risks/complications for exercising at high intensities.

Procedures: Participation is voluntary and you are free to terminate your participation at any point. Completion of the study will take approximately 3 to 6 weeks, depending on scheduling of the visits. During these visits you will be asked to do the following things:

Baseline visit: You will need to refrain from eating or exercising for 3 hours prior to this visit, which will take approximately 1-1.5 hours and include the following activities: 
- Informed consent: You will read this form which explains the procedures that will be used for the experiment. We will also provide a copy of this form to you and provide ample time to discuss any questions or concerns you may have.

- Questionnaire: You will be asked to complete two questionnaires regarding how much you currently exercise. You will also complete a questionnaire pertaining to your current health status as well as the health of your immediate family. This questionnaire will help to screen for any exercise related health risk.

- Blood pressure measurements: Your resting blood pressure will be measured.

- Body size measurements: Your height, weight, and the circumference of your waist and hips will be measured. You will be asked to remove loose fitting clothing such as sweatshirts and sweatpants.

- Body composition: Your body composition will be measured using two different techniques. You will be asked to wear spandex or compression type clothing for one of the tests.

- Sub-maximal treadmill test: This test will help us to measure the maximum intensity that you can exercise at. The test involves a series of exercise stages that will get progressively harder. During the test you will have a mouthpiece and nose clip on so that you can only breathe through the mouthpiece. You will not exercise at maximal intensity during the test and are free to stop the test at any point.

HIIT practice sessions: You will need to refrain from eating or exercising for 3 hours prior to this visit, which will take approximately 1 hour and include the following activities:

1) Resting blood pressure measurement. Your resting blood pressure will be measured.

2) High Intensity Interval Training Practice. This session will allow you to practice the different intensities for the experimental exercise sessions on the treadmill. You will be asked to complete a few repetitions at different speeds and inclines to allow for the researchers to determine the speed and incline that will elicit the desired intensities, based on heart rate, during the exercise sessions. Once the proper intensities are determined, we will ask you to complete a maximum of 5 HIIT cycles consisting of high and low intensity for a total of 60 seconds at each repetition (Eg. 60 seconds at a high intensity followed by 60 seconds at a low intensity, followed by 4 more cycles). This may take a few practice sessions, on separate days, in order to reach the 5 cycles and feel as comfortable as possible with the exercise sessions. You may stop at any time.

\section{Condition 1}

You will be asked to not consume any food at least 3 hours before the exercise session as stomach pain during high intensity exercise has been experienced in the past.. You should drink plenty of water so that you are well hydrated throughout the study. This visit will take approximately $1.5-2$ hours to complete the uphill walking protocol. You will warm up for 5 minutes and then walk for 40 minutes, uphill. You will then have a 2 minute cooldown. You may stop the test at any point. Water will be 
provided for you to drink during this exercise bout. You will assess how hard you think the exercise is as well as how much you are enjoying the exercise session at multiple times during the walk..

At the end of the exercise session, you will be asked to sit next to the treadmill where we will ask you to wear a mouth piece and nose clip for 3 minutes a few times following the treadmill walking session. You will also be asked to complete two questionnaires, at two time points, about how you currently feel and how much you enjoyed the exercise.

Upon the completion of the questionnaires, there will be a short one-on-one interview regarding the recently completed exercise session. Following the interview, you are free go. A small snack will be provided to you if you would like.

A randomized order of the 3 exercise conditions will result in the 3 conditions to be performed in an order that you and the researchers will not know until you arrive to the laboratory.

\section{$\underline{\text { Condition } 2}$}

This visit will take approximately 1-1.5 hours. Once ready, you will warm up on the treadmill for 5 minutes. You will then complete 10 cycles of 60 second high intensity/low intensity. The intensity will be increased and decreased by changing the incline and speed of the treadmill. At the end of each stage, you will be asked to identify how hard the exercise is and how much you are enjoying the exercise. After the 10 cycles of high/low intensity, you will complete a 2 minute cool down session at a speed that is comfortable for you. You will assess how hard you think the exercise is as well as how much you are enjoying the exercise session at multiple times during the walk..

Following the exercise session, you will complete the same questionnaires and wear the oxygen mouth piece just like you did in condition 1.

\section{Condition 3}

This visit will take between 1-1.5 hours. Once ready, you will warm up on the treadmill for 5 minutes. You will then complete 7 cycles of 90 second high/low intensity. The intensity will be changed by increasing or decreasing the incline and speed of the treadmill. At the end of each stage, you will be asked to identify how hard and how much you are enjoying the exercise session. You will then complete a 2 minute cool down at a speed that is comfortable to you once the 7 cycles of high/low intensity are complete. You will assess how hard you think the exercise is as well as how much you are enjoying the exercise session at multiple times during the walk..

Following the exercise session, you will complete the same questionnaires and wear the oxygen mouth piece just like you did in condition 1 and condition 2 .

Risks: There are side effects and risks involved from doing certain activities. These side effects are often called risks, and for this project, the risks are:

1) People who are claustrophobic may be uncomfortable in the chamber used to determine body composition. If needed, participants can open the chamber door at any time. 
2) The sub-maximal exercise tests will likely make you feel uncomfortable in the last stages, possibly leaving you a little bit fatigued. This sub-maximal test is commonly used in clinical procedures for clinical diagnostics and disease evaluation. People rarely have adverse side effects, but some have occurred before. There is a low risk of sudden death with approximately 1 in 10,000 tests, and serious complications such as abnormal heart rhythm or chest pain for prolonged periods of time present in about 4 out of every 10,000 tests. You can stop at any time.

3) The uphill walking protocol will be performed at a moderate intensity of exertion. However, the exercise is likely to produce fatigue during and up to a few hours following the exercise. People rarely have adverse side effects, but some have occurred before. There is the risk for serious injury like a muscle pull or strain from the exercise, but this is minimal in healthy individuals who do not have cardiovascular, metabolic, or musculoskeletal problems and have not had recent surgery. You can stop at any time. Some people may feel lightheadedness or nausea.

4) The high intensity interval training protocol will be performed at both high intensity and low intensity levels. This exercise session will most likely result in levels of fatigue during and up for several hours following the exercise session. Past research with high intensity interval training has seen few adverse side effects, some have occurred. There is the risk for serious injury like a muscle pull or strain from the exercise, but this is minimal in healthy individuals who do not have musculoskeletal problems and have not had recent surgery. There is also some risk of a cardiovascular event, though past research has shown few adverse side effects in the healthy population. You are free to stop the exercise bout at any time. Some people have experienced nausea, lightheadedness, and stomach pains during and after the exercise bout.

Benefits: You may gain some benefits by participating in this study, such as:

1) You will receive information about your level of cardiovascular fitness, blood pressure, as well as the findings of the study with the intent to further improve your exercise training regimen.

No other benefits are promised to you.

Compensation: You will receive ten dollars per exercise session in the laboratory. Compensation will be given at the end of your final visit. You will receive compensation for the exercise sessions that you complete even if you choose to terminate participation in the study.

Freedom of Consent: You have the right to withdraw from participating in the study at any time with a no questions asked policy. You may withdraw in writing, over the phone (to John Halvorson at 509-8817119 or Mary Miles at 406-994-6678), or in person. If you withdraw, you will not lose any benefits you incurred up to the time of withdrawal. Your participation in this study is completely voluntary.

Funding: This study is not funded by any outside agencies.

Please ask any questions: You are encouraged by the researcher to ask any and all questions you may have, as well as addressing any concerns about the study. The researcher will answer your questions as 
Informed Consent Document (continued)

fully and as accurately as possible. Your peace of mind and comfort in the study is of utmost importance to the researcher.

Confidentiality: All data and information received from you for this study will be kept completely confidential. You will be given a subject identification number that will be used to describe all data. This data will be kept locked in a file cabinet in the Nutrition Research Laboratory. This information could be published in scientific and/or medical journals, but your identity will remain confidential. If you withdraw from the study at any time, all of your information will be deleted from the study records, and you will not be contacted again regarding the study. There are absolutely no penalties for withdrawing.

In the unlikely event of injury to you due to participation in this study, medical treatments such as first aid and help getting to adequate health care providers (such as transport to Bozeman Health) will be

provided, however, there is no compensation for any of this provided by Montana State University. You can access further information involving this policy and treatment by contacting John Halvorson at 9945001, or emailing him at john.halvorson1@msu.montana.edu. You may also contact, Mary Miles at 9946678, or emailing her at mmiles@montana.edu.

Any other questions you may have regarding your rights as a participant may be answered by the chairman of the Human Subjects Committee, Mark Quinn. He can be reached at 406-994-4707. 


\section{STATEMENT OF AUTHORIZATION}

Study Title: The perceptual responses to high intensity interval training.

\section{VISIT 1:}

AUTHORIZATION: By signing this document, I acknowledge that I have read the above and I understand the discomforts, inconvenience, and risks associated with my participation in this study. I, (name of subject), agree to participate in this study. I fully understand that I may later refuse participation at any time, and may withdraw from the study at that time. I have been given a copy of this consent form for my own records.

Signed:

Date:

Investigator:

Date:

VISIT 2:

AUTHORIZATION: By signing this document, I acknowledge that I have read the above and I understand the discomforts, inconvenience, and risks associated with my participation in this study. I, (name of subject), agree to participate in this study. I fully understand that I may later refuse participation at any time, and may withdraw from the study at that time. I have been given a copy of this consent form for my own records.

Signed:

Date:

Investigator:

Date:

\section{CONDITION 1:}

AUTHORIZATION: By signing this document, I acknowledge that I have read the above and I understand the discomforts, inconvenience, and risks associated with my participation in this study. I, (name of subject), agree to participate in this study. I fully understand that I may later refuse participation at any time, and may withdraw from the study at that time. I have been given a copy of this consent form for my own records.

Signed:

Date:

Investigator: Date: 
Informed Consent Document (continued)

\section{CONDITION 2:}

AUTHORIZATION: By signing this document, I acknowledge that I have read the above and I understand the discomforts, inconvenience, and risks associated with my participation in this study. I, (name of subject), agree to participate in this study. I fully understand that I may later refuse participation at any time, and may withdraw from the study at that time. I have been given a copy of this consent form for my own records.

Signed:

Date:

Investigator:

Date:

\section{CONDITION 3:}

AUTHORIZATION: By signing this document, I acknowledge that I have read the above and I understand the discomforts, inconvenience, and risks associated with my participation in this study. I, (name of subject), agree to participate in this study. I fully understand that I may later refuse participation at any time, and may withdraw from the study at that time. I have been given a copy of this consent form for my own records.

Signed:

Date:

Investigator:

Date: 
APPENDIX C:

RATINGS OF PERCEIVED EXERTION 


\section{RATING OF PERCEIVED EXERTION}

6

7

8

9

10

11

12

13

14

15

16

17

18

19

20
NO EXERTION AT ALL

EXTREMELY LIGHT

VERY LIGHT

LIGHT

SOMEWHAT HARD

HARD (HEAVY)

VERY HARD

EXTREMELY HARD

MAXIMAL EXERTION 
APPENDIX D:

EXERCISE ENJOYMENT SCALE 


\section{EXERCISE ENJOYMENT SCALE}

INSTRUCTIONS: Use the following scale to indicate how much you are enjoying this exercise session.

Not at all

2

Very little

3

Slightly

4

Moderately

5

Quite a bit

6

Very much

7

Extremely 
APPENDIX E:

FEELING SCALE 


\section{FEELING SCALE}

Instructions: Please rate how you currently feel.

$\begin{array}{ll}+5 & \text { Very Good } \\ +4 & \\ +3 & \text { Good } \\ +2 & \\ +1 & \text { Slightly Good } \\ 0 & \text { Neutral } \\ -1 & \text { Slightly bad } \\ -2 & \\ -3 & \text { Bad } \\ -4 & \\ -5 & \text { Very bad }\end{array}$




\section{APPENDIX F:}

PHYSICAL ACTIVITY ENJOYMENT SCALE 


\section{PHYSICAL ACTIVITY ENJOYMENT SCALE}

\section{Instructions:}

Please rate how you feel at this moment about the exercise you recently completed by circling the appropriate numbers.

\begin{tabular}{|c|c|c|c|}
\hline 1 & I enjoyed it & 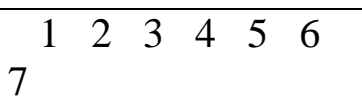 & I hated it \\
\hline 2 & I felt bored & $\begin{array}{lllllll}1 & 2 & 3 & 4 & 5 & 6 & 7 \\
\end{array}$ & I felt interested \\
\hline 3 & I disliked it & $\begin{array}{lllllll}1 & 2 & 3 & 4 & 5 & 6 & 7 \\
\end{array}$ & I liked it \\
\hline 4 & I found it pleasurable & $\begin{array}{lllllll}1 & 2 & 3 & 4 & 5 & 6 & 7 \\
\end{array}$ & I found it unpleasable \\
\hline 5 & $\begin{array}{l}\text { I was very absorbed in the } \\
\text { activity }\end{array}$ & $\begin{array}{lllllll}1 & 2 & 3 & 4 & 5 & 6 & 7\end{array}$ & $\begin{array}{l}\text { I was not at all absorbed in } \\
\text { the activity }\end{array}$ \\
\hline 6 & It was no fun at all & $\begin{array}{lllllll}1 & 2 & 3 & 4 & 5 & 6 & 7 \\
\end{array}$ & It was a lot of fun \\
\hline 7 & I found it energizing & $\begin{array}{lllllll}1 & 2 & 3 & 4 & 5 & 6 & 7 \\
\end{array}$ & I found it tiring \\
\hline 8 & It made me depressed & $\begin{array}{lllllll}1 & 2 & 3 & 4 & 5 & 6 & 7 \\
\end{array}$ & It made me happy \\
\hline 9 & It was very pleasant & $\begin{array}{lllllll}1 & 2 & 3 & 4 & 5 & 6 & 7 \\
\end{array}$ & It was very unpleasant \\
\hline 10 & $\begin{array}{l}\text { I felt good physically while } \\
\text { doing it }\end{array}$ & $\begin{array}{lllllll}1 & 2 & 3 & 4 & 5 & 6 & 7\end{array}$ & $\begin{array}{l}\text { I felt bad physically while } \\
\text { doing it }\end{array}$ \\
\hline 11 & It was very invigorating & $\begin{array}{lllllll}1 & 2 & 3 & 4 & 5 & 6 & 7\end{array}$ & $\begin{array}{l}\text { It was not at all } \\
\text { invigorating }\end{array}$ \\
\hline 12 & I was very frustrated by it & $\begin{array}{lllllll}1 & 2 & 3 & 4 & 5 & 6 & 7\end{array}$ & $\begin{array}{l}\text { I was not at all frustrated by } \\
\text { it }\end{array}$ \\
\hline 13 & It was very gratifying & $\begin{array}{lllllll}1 & 2 & 3 & 4 & 5 & 6 & 7 \\
\end{array}$ & It was not at all gratifying \\
\hline 14 & It was very exhilarating & $\begin{array}{lllllll}1 & 2 & 3 & 4 & 5 & 6 & 7 \\
\end{array}$ & It was not at all exhilarating \\
\hline 15 & It was not stimulating at all & $\begin{array}{lllllll}1 & 2 & 3 & 4 & 5 & 6 & 7 \\
\end{array}$ & It was very stimulating \\
\hline 16 & $\begin{array}{l}\text { It gave me a strong sense } \\
\text { of accomplishment }\end{array}$ & $\begin{array}{lllllll}1 & 2 & 3 & 4 & 5 & 6 & 7\end{array}$ & $\begin{array}{l}\text { It did not give me a strong } \\
\text { sense of accomplishment }\end{array}$ \\
\hline 17 & It was very refreshing & $\begin{array}{lllllll}1 & 2 & 3 & 4 & 5 & 6 & 7 \\
\end{array}$ & It was not at all refreshing \\
\hline 18 & $\begin{array}{l}\text { I felt as though I would } \\
\text { rather be doing something } \\
\text { else }\end{array}$ & $\begin{array}{lllllll}1 & 2 & 3 & 4 & 5 & 6 & 7\end{array}$ & $\begin{array}{l}\text { I felt as though there was } \\
\text { nothing else I would rather } \\
\text { be doing }\end{array}$ \\
\hline
\end{tabular}


APPENDIX G:

PREFERENCE ORDER 


\section{Preference Order}

Instructions: Please order the three exercise sessions based on your preference from most preferred (1) to least preferred (3).

Continuous Aerobic Walking:

High Intensity Interval Training with 60 second reps:

High Intensity Interval Training with 90 second reps: 